\title{
RESCUING THE STRONG PRECAUTIONARY PRINCIPLE FROM ITS CRITICS
}

Noah M. Sachs*

The Strong Precautionary Principle, an approach to risk regulation that shifts the burden of proof on safety, can provide a valuable framework for preventing harm to human health and the environment. Cass Sunstein and other scholars, however, have consistently criticized the Principle, rejecting it as paralyzing, inflexible, and extreme.

In this reassessment of the Strong Precautionary Principle, I highlight the significant benefits of the Principle for risk decision making, with the aim of rescuing the Principle from its dismissive critics. The Principle sends a clear message that firms must research the health and environmental risks of their products, before harm occurs. It does not call for the elimination of all risk, nor does it ignore tradeoffs, as Sunstein has alleged. Rather, through burden shifting, the Principle legitimately requires risk creators to research and justify the risks they impose on society. By exploring where the Principle already operates successfully in U.S. law-examples often overlooked by the critics - I highlight the Principle's flexibility and utility in regulatory law.

This Article uses chemical regulation as a case study in how the Principle can guide Congress in an ongoing controversy. Congress is considering a major overhaul of the flawed Toxic Substances Control Act of 1976 (TSCA), and this change could be one of the most significant developments in environmental law in a generation. This Article advocates implementing the Strong Precautionary Principle in a replacement statute for TSCA. Under my proposed licensing system, chemical manufacturers would carry the burden to demonstrate that their products do not pose significant risks to human health or the en-

* Associate Professor, University of Richmond School of Law and Director, Robert R. Merhige, Jr. Center for Environmental Studies. This paper was presented at the Virginia Junior Faculty Forum in May 2010, at the New Scholars Workshop at the annual conference of the Southeastern Association of Law Schools in July 2010, and at a workshop sponsored by the Center for Progressive Reform in February 2011. Many thanks to John Applegate, Doug Kysar, Mitchell Crusto, Jessica Erickson, Corinna Lain, Jim Gibson, Meredith Harbach, and Kevin Walsh, who provided helpful comments on drafts, and to Carla Pool for invaluable research assistance. 
vironment. The TSCA example shows that the Strong Precautionary Principle is not a vague abstraction, as critics have alleged, but can instead provide practical guidance for strengthening a troubled, and underprotective, chemical regulatory regime.

\section{TABLE OF CONTENTS}

Introduction 1286

I. Strong Precaution and Risk Regulation ......................................1292

A. Defining the Terms...............................................................1292

1. The Weak Precautionary Principle .................................1292

2. The Strong Precautionary Principle................................1295

B. The Salutary Signals of Strong Precaution .............................1299

II. Rescuing the Strong Precautionary Principle from Its Critics ......1304

A. The Critics' Complaints ……...................................................1305

B. Countering the Critics...........................................................1307

1. Strong Precaution in Existing Law .................................1307

2. Countering the Critique of Extremism............................1311

3. Countering the Critique of "Paralysis" ..........................1316

a. The Problem of Tradeoffs in Legislation ..............1317

b. Addressing Tradeoffs Within

Precautionary Legislation

C. The Limits of Strong Precaution...............................................1325

III. Implementing Strong Precaution in Chemical Regulation............1327

A. The Hollow Hope of TSCA …………..................................1327

B. Toward the Next Generation of Chemical Regulation ..........1331

1. Precautionary Research Requirements...........................1331

2. Shifting the Burden of Proof ..........................................1333

a. Precautionary Triggers ..........................................1334

b. Regulatory Offramps .............................................1336

Conclusion 1338

\section{INTRODUCTION}

The Toxic Substances Control Act of 1976 (TSCA), ${ }^{1}$ designed to protect Americans from the risks of chemicals introduced into commerce, is now widely viewed by scholars and governmental experts as flawed and underprotective. ${ }^{2}$ The U.S. chemical industry produces or

1. Toxic Substances Control Act, 15 U.S.C. $\$ \S 2601-2692$ (2006).

2. For scholarly criticisms of the Toxic Substances Control Act (TSCA), see John S. Applegate, Synthesizing TSCA and REACH: Practical Principles for Chemical Regulation Reform, 35 ECOLOGY L.Q. 721 (2008); Noah M. Sachs, Jumping the Pond: Transnational Law and the Future of Chemical Regulation, 62 VAND. L. REV. 1817 (2009); Wendy E. Wagner, Commons Ignorance: The Failure of Environmental Law to Produce Needed Information on Health and the Environment, 53 DUKE L.J. 1619 (2004). For governmental criticisms of TSCA, see U.S. GOV'T ACCOUNTABILITY OFFICE, GAO09-428T, CHEMICAL REgulation: OptIONS FOR ENHANCING THE EFFECTIVENESS OF THE TOXIC 
imports more than seventy-three billion pounds of chemicals per day, ${ }^{3}$ yet TSCA does not require any form of routine chemical risk assessment. As a result, we lack basic toxicity data for the vast majority of chemicals used in cookware, toys, beauty products, food packaging, and other items. The potential population-wide harm is sobering. Carcinogenic chemicals once thought to be safely contained in consumer products are now present in the bloodstream and tissues of virtually all Americans. ${ }^{4}$

Many interest groups are calling for an overhaul of TSCA. In 2010, landmark TSCA reform bills were introduced in both houses of Congress, ${ }^{5}$ and principles to guide the reform effort have been announced by the Environmental Protection Agency (EPA), ${ }^{6}$ various U.S. states, ${ }^{7}$ environmental groups ${ }^{8}$ and the largest chemical industry trade association, the American Chemistry Council. ${ }^{9}$ Even if Congress does not act on TSCA reform this term, states may step in to enact their own toxics regulatory regimes, as some states have done already. ${ }^{10}$

The current interest in new approaches to chemical regulation provides an important opportunity to question prevailing U.S. frameworks for risk regulation. What regulatory authority should legislators confer on agencies to protect public health from toxic chemicals and other risks? Who should bear the burden of proof on whether products or activities that may pose serious risks should be allowed in commerce? And should inevitable scientific uncertainty about the exact nature of a risk cut in favor of regulation, or against it?

SUBSTANCES CONTROL ACT (2009) [hereinafter GAO, ENHANCING TSCA]; U.S. GOV'T ACCOUNTABILITY OfFICE, GAO-05-458, CHEMICAL REgulation: OPTIONS EXIST TO IMPROVE EPA's AbILITY to AsSess Health Risks and MaNage Its Chemical Review Program (2005) [hereinafter GAO, OPTIONS EXIST].

3. See Office of Pollution Prevention \& Toxics, U.S. EnVtl. Prot. Agency, 2006 INVENTORY UPDATE REPORTING: DATA SUMMARY 15 (2008), http://www.epa.gov/iur/pubs/ 2006_data_summary.pdf (reporting approximately twenty-seven trillion pounds of chemicals produced or imported in the United States in 2005). This figure is likely an underestimate of total U.S. chemical production, because low-volume chemical production, below 25,000 pounds per year at one site, did not need to be reported to the Environmental Protection Agency (EPA). Id. at 1 .

4. See Dep't of Health \& Human Servs. et al., Fourth National Report on Human EXPOSURE TO ENVIRONMENTAL CHEMICALS (2009), http://www.cdc.gov/exposurereport/pdf/Fourth Report_ExecutiveSummary.pdf; Tracey J. Woodruff et al., Environmental Chemicals in Pregnant Women in the US: NHANES 2003-2004, ENVTL. HEALTH PERSP. 878, 879 tbl.1 (2011); see also Richard A. Denison, Ten Essential Elements in TSCA Reform, 39 ENVTL. L. REP. 10020, 10023 (2009).

5. Safe Chemicals Act of 2010, S. 3209, 111th Cong. (2010); Toxic Chemicals Safety Act of 2010, H.R. 5820, 111th Cong. (2010).

6. See U.S. Envtl. Prot. Agency, Essential Principles for Reform of Chemicals MANAGEMENT LEGISLATION (2010), http://www.epa.gov/oppt/existingchemicals/pubs/principles.pdf.

7. See States' Principles on Reform of the Toxic Substances Control Act (Dec. 2, 2009), http://www.saferstates.com/attachments/StatePrinciples.pdf.

8. See Safer Chemicals, Healthy families, A Platform for Reform of the Toxic SUBSTANCES CONTROL ACT (Aug. 4, 2009), http://www.saferchemicals.org/PDF/SCHF_Campaign_ Platform.pdf.

9. See AM. CHEMISTRY COUNCIL, 10 PRINCIPLES FOR MODERNIZING TSCA (2009), http://www. americanchemistry.com/Policy/Chemical-Safety/TSCA/10-Principles-for-Modernizing-TSCA.pdf.

10. See Linda Breggin, A Critical Juncture in Fed-State Roles, ENVTL. F., Jan.-Feb. 2011, at 10 (discussing recent toxics regulatory initiatives in California, Massachusetts, and Washington). 
In this Article, which builds on my prior study of TSCA reform, ${ }^{11}$ I use the chemical regulation debate as a lens for a broader reassessment of a controversial approach to risk management, called the Strong Precautionary Principle. The Strong Precautionary Principle shifts the burden of proof on the safety of a product or activity from government regulators to private firms. I define it as the view that: (1) regulation should presumptively be applied when an activity or product poses serious threats to human health or the environment, even if scientific uncertainty precludes a full understanding of the nature or extent of the threats; and (2) the burden of overcoming the presumption in favor of regulation lies with the proponent of the risk-creating activity or product. ${ }^{12}$

The Strong Precautionary Principle can be contrasted with the dominant regulatory framework in the United States, in which government agencies usually bear the burden of proof to show unacceptable risk prior to restricting a product or activity. TSCA's requirement that the EPA prove "unreasonable risk" to restrict a chemical is emblematic of that regulatory approach, and that choice to put the burden of proof on the EPA has crippled chemical regulation in the United States. ${ }^{13}$ According to Dr. Lynn Goldman, who oversaw TSCA implementation during the Clinton Administration, TSCA will "never be effective" unless it is amended to shift the burden of proof on chemical safety to chemical manufacturers. ${ }^{14}$

A preventive regulatory framework grounded in a shift in the burden of proof is attractive for a number of reasons, yet prior literature on the Strong Precautionary Principle has been almost uniformly critical. Cass Sunstein, John Graham, Jonathan Wiener, and other critics of the Principle have little interest in its further application in TSCA, or elsewhere. Instead, they want to bury it. Sunstein has derided Strong Precaution as "senseless,"15 "paralyzing,"16 and "worse than unhelp-

11. See Sachs, supra note 2 .

12. A variety of definitions for the Strong Precautionary Principle may be found in the literature. Two common elements of the Principle are an anticipatory approach to managing risks and a shift in the burden of proof on whether a risky activity should be allowed to proceed. See CASS R. SUNSTEIN, Laws of Fear: Beyond the Precautionary PrinCIPle (2005); A.W. Harris, Derogating the Precautionary Principle, 19 VILL. ENVTL. L.J. 1, 63 (2008); Justin Wade, Sunstein's Blunder; Or, the Perils of Reconstructing Precaution, 20 GEO. INT'L ENVTL. L. REV. 473, 485 (2008).

13. The term "unreasonable risk" occurs more than thirty-five times in the text of TSCA, and in every case the EPA bears the burden to prove "unreasonable risk" for a chemical. JOHN $S$. APPLEgate ET Al., ThE REgulation OF TOXIC SubSTANCES AND HAZARDOUS Wastes 276 (2d ed. 2011). Most importantly, the EPA bears the burden of proving "unreasonable risk" in the crucial provisions of TSCA Section 6, governing restrictions on hazardous chemicals. 15 U.S.C. $\$ 2605$ (a) (2006). For a discussion of the problems with the vague "unreasonable risk" standard and a governmental burden of proof in chemical regulation, see John S. Applegate, The Perils of Unreasonable Risk: Information, Regulatory Policy, and Toxic Substances Control, 91 CoLUM. L. REV. 261 (1991).

14. Toxic Substances Control Act and the Chemicals Management Program at EPA: Hearing Before the S. Comm. on Env't \& Pub. Works, 109th Cong. 75 (2006) (statement of Lynn R. Goldman, Professor, Environmental Health Services, Johns Hopkins University).

15. Cass R. Sunstein, Beyond the Precautionary Principle, 151 U. PA. L. REv. 1003, 1008 (2003).

16. Id. at 1004 . 
ful." $17 \mathrm{He}$ and other detractors have charged that the Principle is excessively risk averse, provides no guidance on which risks to address, and ignores so-called "risk-risk" tradeoffs in which a precautionary response to one "target" risk may lead to substitute risks that are even worse. ${ }^{18}$ The Principle should be rejected, wrote Sunstein, "not because it leads in bad directions, but because it leads in no direction at all. The principle is literally paralyzing - forbidding inaction, stringent regulation, and everything in between." 19

This sharply critical scholarship is not a mere academic sideshow to the Beltway battle over chemical regulation. ${ }^{20}$ If influential scholars and key policy makers maintain that the Strong Precautionary Principle is illegitimate, then it is unlikely that TSCA will be reformed in a meaningful way. Congress may miss a once-in-a-generation opportunity to repair the moribund chemical regulatory system.

The stakes are high, yet few scholars have offered any sustained defense of Strong Precaution. Most scholars of the role of precaution in risk regulation have instead kept to the safer terrain of defending socalled "weak" versions of the Precautionary Principle, which do not involve burden shifting. ${ }^{21}$ While literature advocating "weak" precaution is voluminous, ${ }^{22}$ the scholarly terrain on the Strong Precautionary Principle

17. Cass R. Sunstein, Your Money or Your Life, NEw RePUBliC, Mar. 5, 2004, at 27, 30. See also Aaron WildavsKy, BUT Is IT TRuE? A CITIZEN'S Guide to ENVIRONMENTAL HEALTH AND SAFETY ISSUES, 429-30 (1995) (stating profound objections to the Precautionary Principle's reversal of causality, in which individuals and businesses must prove that they will do no harm).

18. See, e.g., Jonathan H. Adler, More Sorry Than Safe: Assessing the Precautionary Principle and the Proposed International Biosafety Protocol, 35 TEX. INT'L L.J. 173, 195 (2000) ("The problem is that by focusing on one set of risks - those posed by the introduction of new technologies with somewhat uncertain effects - the precautionary principle turns a blind eye to the harms that occur, or are made worse, due to the lack of technological development."); Sunstein, supra note 15, at 1020 ("The most serious problem with the strong version of the precautionary principle is that it offers no guidance-not that it is wrong, but that it forbids all courses of action, including inaction."); Jonathan Baert Wiener \& John D. Graham, Resolving Risk Tradeoffs, in RISK VERSUS RISK: TradeOFFS IN ProteCTING HEALTH AND THE ENVIRONMENT 226, 226 (John D. Graham \& Jonathan Baert Wiener eds., 1995) ("Each intervention to protect against a target risk can simultaneously generate countervailing risks; these risk tradeoffs at least reduce the gross benefits of the intervention and in some cases mean that the intervention will do more harm than good.").

19. Sunstein, supra note 15 , at 1003.

20. Sunstein heads the influential Office of Information and Regulatory Affairs (OIRA) in the Executive Office of the President. See Benjamin Wallace-Wells, Cass Sunstein Wants to Nudge Us, N.Y. TIMES MAG., May 16, 2010, at 38 (describing Sunstein's role at OIRA and his involvement in Obama Administration debates over cost-benefit analysis, valuation of human life, and climate change).

21. I define terms, including the differences between "weak" and "strong" versions of the Precautionary Principle, infra, Part I. Clarity of definitions is vital. Confusing and inconsistent definitions of "precaution" and "precautionary principle" have clouded the scholarship in this area for decades.

22. See, e.g., John S. Applegate, Embracing a Precautionary Approach to Climate Change, in EConomic Thought ANd U.S. Climate Change Policy 171 (David M. Driesen ed., 2010) [hereinafter Applegate, Climate Change]; John S. Applegate, The Taming of the Precautionary Principle, 27 WM. \& MARY ENVTL. L. \& POL'Y. REV. 13 (2002) [hereinafter Applegate, The Taming]; Douglas A. Kysar, It Might Have Been: Risk, Precaution and Opportunity Costs, 22 J. LAND UsE \& ENVTL. L. 1 (2006); Elizabeth Fisher, Opening Pandora's Box: Contextualising the Precautionary Principle in the European Union, in UNCERTAIN RISKS REgULATED 21 (Michelle Everson \& Ellen Vos eds., 2009); 
has been ceded to its opponents. ${ }^{23}$ Under their avalanche of criticism, some breathing space is urgently needed to reconsider the merits and practical applications of Strong Precaution. Indeed, resuscitating TSCA as an effective chemical regulatory regime depends, in no small part, on rescuing the Strong Precautionary Principle from its critics.

This Article undertakes this much-needed reassessment of the Strong Precautionary Principle. It proceeds in three Parts. In Part I, I provide a brief introduction to the concept of precaution in risk regulation, distinguishing the Strong Precautionary Principle from its weaker cousins. Then, directly considering the merits of Strong Precaution, I justify it instrumentally, as an incentive to develop information on health and environmental risks, and deontologically, as a confirmation of the moral obligations of those who seek to market potentially hazardous products.

Part II counters the critics' objections to the Strong Precautionary Principle. Cass Sunstein and other critics contend that Strong Precaution represents a new and untested alternative to dominant risk-management paradigms such as cost-benefit analysis. ${ }^{24}$ I show, on the other hand, that Strong Precaution is already deeply rooted in U.S. law. It forms the basis for numerous licensing, permitting, and preapproval programs that are cornerstones of public health and environmental protection in the United States. The Food and Drug Administration's review process for new drugs is just one of myriad examples. ${ }^{25}$

I also show in Part II that the Principle is not inflexible, extreme, or cost insensitive, as the Principle's detractors would have us believe. Sunstein's claim that Strong Precaution inevitably leads to "paralysis" is a hyperbolic mischaracterization. Applied properly, the Strong Precautionary Principle helps to uncover regulatory alternatives and permits

Gregory N. Mandel \& James Thuo Gathii, Cost-Benefit Analysis Versus the Precautionary Principle: Beyond Cass Sunstein's Laws of Fear, 2006 U. ILL. L. REV. 1037 (2006); Robert V. Percival, Who's Afraid of the Precautionary Principle?, 23 PACE ENVTL. L. REV. 21 (2005).

23. Advocates of the Strong Precautionary Principle write primarily outside of the legal academy, perhaps reflecting the marginalization of the Principle in past legal scholarship. For work supporting the Principle, see collected essays in PRECAUTION, ENVIRONMENTAL SCIENCE, AND PREVENTIVE Public Policy (Joel A. Tickner ed., 2003); collected essays in Protecting Public HeAlTH \& THE Environment: Implementing the PRecautionaRy Principle (Carolyn Raffensperger \& Joel A. Tickner eds., 1999); Carl F. Cranor, Toward Understanding Aspects of the Precautionary Principle, 29 J. MED. \& PHIL. 259 (2004); Sven Ove Hansson, Can We Reverse the Burden of Proof?, 90 ToxICOLOGY LETTERS 223 (1997).

24. See, e.g., John D. Graham, Admin., Office of Info. \& Regulatory Affairs, The Role of Precaution in Risk Assessment and Management: An American's View, Address at The US, Europe, Precaution and Risk Management: A Comparative Case Study Analysis of the Management of Risk in a Complex World (Jan. 11-12, 2002), http://www.whitehouse.gov/omb/inforeg/eu_speech.html ("[W]e do not recognize any universal precautionary principle. We consider it to be a mythical concept, perhaps like a unicorn."); Lawrence A. Kogan, What Goes Around Comes Around: How UNCLOS Ratification Will Herald Europe's Precautionary Principle As U.S. Law, 7 SANTA CLARA J. INT'L L. 23, 27 (2009) ("[T]he Precautionary Principle ... entails a radical change in outlook.").

25. See discussion of the Principle's application in the FDA review process and other regulatory regimes in Part II, infra. 
considerations of tradeoffs, while raising a wider set of questions than traditional cost-benefit analysis. ${ }^{26}$ The Principle is not antithetical to a weighing of the costs and benefits of regulatory action. Indeed, critics overlook that a cost-benefit test could be applied within a Strong Precautionary framework, by requiring that the proponent of a risky activity prove that the benefits of the activity outweigh the costs (shifting that analytical burden off the government).

While Part II discusses some potential linkages between cost-benefit analysis and Strong Precaution, I conclude, ultimately, that utilitarian welfare maximization should not be the sole criterion for risk decision making. The Strong Precautionary Principle is most attractive in contexts where traditional cost-benefit analysis is ill-suited. These contexts involve pervasive uncertainty about the gravity of harm that might result from an activity or the frequency of its occurrence, or compelling equity or distributional concerns. Legislators may opt for a Strong Precautionary framework for a variety of legitimate reasons, including protection of crucial ecosystem functions, protection of future generations, or providing government review over the location or size of activities that may harm the public. Moreover, the Principle's encouragement of ex ante, premarket review of risks does clearly distinguish the Principle from dominant risk management frameworks.

I concede in Part II that the Strong Precautionary Principle should not be applied dogmatically as a universal framework for managing every risk our society faces. More decentralized approaches, including tort liability and contractual informed consent, are often suitable for addressing discrete risks that affect relatively few parties. Critics intent on blasting Strong Precaution are ignoring, however, the Principle's "contextual rationality." 27 That is, they are ignoring the arenas of risk management, such as chemical regulation, where the Principle's default presumptions, burden shifting, and ex ante review of risks are eminently sensible.

In Part III, I take up the question of TSCA reform directly, showing how the Strong Precautionary Principle could be incorporated in concrete statutory provisions while avoiding the parade of horribles alleged by the critics. I advocate priority setting through certain "precautionary triggers" that would compel more extensive review of the most hazardous classes of chemicals. I also advocate shifting the burden of proof for these chemicals and allowing limited avenues for continued marketing of such chemicals (which I call "regulatory offramps") if the manufacturer can demonstrate that the chemical can be used safely. Shifting the bur-

26. See Joel A. Tickner, A Map Toward Precautionary Decision Making, in Protecting Public HeALTH \& THE ENVIRONMENT, supra note 23, at 162, 163 (noting that the Precautionary Principle asks a different set of questions from traditional risk assessment: "How much contamination can be avoided while still maintaining necessary values?'; 'What are the alternatives to this activity that achieve a desired goal... ?'; and 'Do we need this activity in the first place?').

27. David Dana, The Contextual Rationality of the Precautionary Principle, 35 QUEEN's L.J. 67, 68 (2009). 
den of proof is, to be sure, just one element of dozens of needed changes in TSCA. It is also the game changer. It will dramatically alter incentives, loosen informational bottlenecks, and end our blithe acceptance of "flying blind" in chemical risk management.

\section{StRong PRECAUTION AND Risk REgUlation}

Precaution in risk regulation is controversial, in part, because of a lack of consensus on what precaution means. A vast number of verbal formulations have been developed to describe the concept of precaution, from the simplistic "better safe than sorry" to complicated, multipart definitions. ${ }^{28}$ Collectively, these formulations are often called the Precautionary Principle, but more accurately they should be called Precautionary Principles, because they vary widely and are not synonymous with each other. In this Part, I distinguish "weak" versions of the Precautionary Principle from "strong" versions, clearing some definitional disarray. I then directly address the merits of the Strong Precautionary Principle as a framework for addressing health and environmental risks.

\section{A. Defining the Terms}

\section{The Weak Precautionary Principle}

"Weak" versions of the Precautionary Principle stand for the proposition that regulators should be empowered to address risk in contexts of scientific uncertainty - that is, even before regulators fully understand the nature or extent of risk. One widely cited "weak" version of the Precautionary Principle is contained in the Rio Declaration, adopted by consensus by 172 countries (including the United States) at the Earth Summit in 1992. ${ }^{29}$ Principle 15 of the Rio Declaration states:

In order to protect the environment, the precautionary approach shall be widely applied by States according to their capabilities. Where there are threats of serious or irreversible damage, lack of full scientific certainty shall not be used as a reason for postponing cost-effective measures to prevent environmental degradation. ${ }^{30}$

28. See, e.g., James E. Hickey, Jr. \& Vern R. Walker, Refining the Precautionary Principle in International Environmental Law, 14 VA. ENVTL. L.J. 423, 432-36 (1995) (identifying fourteen "articulations of the Precautionary Principle in the major environmental instruments"); Per Sandin, Dimensions of the Precautionary Principle, 5 HUM. \& ECOLOGICAL RISK ASSESSMENT 889 (1999) (cataloging nineteen different versions of the Precautionary Principle); Joel A. Tickner et al., $A$ Compass for Health: Rethinking Precaution and Its Role in Science and Public Health, 32 INT'L J. EPIDEMIOLOGY 489,489 (2003) (describing the five-part definition of precaution in the 2001 Lowell Statement on Science and the Precautionary Principle).

29. United Nations, UN Conference on Environment and Development (1992), http://www.un. org/geninfo/bp/enviro.html (last visited June 2, 2011).

30. United Nations Conference on Environment and Development, Rio de Janiero, Braz., June 3-14, 1992, The Rio Declaration on Environment and Development, U.N. Doc. A/CONF.151/5/Rev.1 (Jun. 13, 1992), reprinted in 31 I.L.M. 874, 879 (1992). 
This "weak" Precautionary Principle is eminently sensible, with potential applications from water pollution control to natural resource management, public health planning, and global climate change. It reflects that risk assessment is an uncertain science and that serious harm might occur if we postpone regulatory action until all risks from an activity are fully understood. As a 2001 European Environment Agency study, Late Lessons from Early Warnings, documented, there have been numerous cases of governments' inability or refusal to regulate until long after risks were widely known, such as asbestos, DES, tobacco, and mad cow disease. ${ }^{31}$

"Weak" versions of the Precautionary Principle, similar to the Rio Declaration, have been adopted in the Treaty on the Functioning of the European Union, other multilateral treaties, and decisions of international tribunals. ${ }^{32}$ Most of the U.S. environmental and public health statutes passed in the 1970s can be said to incorporate, implicitly, weak precautionary concepts. ${ }^{33}$ Statutes such as the Clean Air Act and the Resource Conservation and Recovery Act have preventive goals, and they allow regulators to act on indications of potential harm from an activity without first obtaining "full" scientific certainty that harm will in fact occur. $^{34}$

Cass Sunstein, who has been the most vociferous critic of Strong Precaution, notably favors embracing the Weak Precautionary Principle in risk regulation. According to Sunstein, that principle suggests "quite sensibly, that a lack of decisive evidence of harm should not be a ground for refusing to regulate." 35 Because the Weak Precautionary Principle

31. See Eur. EnV't Agency, Late Lessons from Early Warnings: The Precautionary PRINCIPLE 1896-2000 (2001).

32. See Consolidated Version of the Treaty on the Functioning of the European Union art. 191, Sept. 5, 2008, 2008 O.J. (C 115) 47, 132 [hereinafter TFEU]; United Nations Conference on Environment and Development: Convention on Biological Diversity, pmbl., June 5, 1992, 31 I.L.M. 818, 822 (1992); United Nations Framework Convention on Climate Change, art. 3(3), May 9, 1992, S. Treaty Doc. No. 102-38 (1992), reprinted in 31 I.L.M. 849, 854 (1992); Bamako Convention on the Ban of the Import into Africa and the Control of Transboundary Movement and Management of Hazardous Wastes Within Africa, art. 4, II 3(f)-(h), Jan. 29, 1991, 30 I.L.M. 773, 781-82 (1991).

33. As John Applegate has noted, while there is no U.S. statute that explicitly references the Precautionary Principle, the Principle is reflected operationally in six kinds of provisions commonly found in U.S. environmental statutes: "planning and alternatives analysis, special regulatory treatment of certain categories of harm, the transition from tort to risk-based regulation, the adoption of margins of safety in standard setting, the policy of erring on the side of safety in risk management, and the shifting of the burden of proof" in some contexts. See John S. Applegate, The Precautionary Preference: An American Perspective on the Precautionary Principle, 6 HUM. \& ECOLOGICAL RISK ASSESSMENT 413, 420 (2000).

34. See Daniel Bodansky, The Precautionary Principle in U.S. Environmental Law, in InTERPRETING tHe PRECAUTIONARY PRINCIPLE 203 (Timothy O'Riordan \& James Cameron eds., 1994). Despite clearly precautionary language in many U.S. environmental and health statutes, many scholars contend that the precautionary thrust of the statutes have been eroded through changes to the U.S. regulatory system since the 1970 s, including comprehensive cost-benefit analysis requirements and more skeptical judicial review. See, e.g., Applegate, supra note 33, at 430-31.

35. SUNSTEIN, supra note 12, at 18; see also Jonathan B. Wiener, Precaution in a Multirisk World, in Human AND ECOlOGiCAl RISK ASSESSMENT: THEORY AND PRACTICE 1509, 1509 (Dennis J. Paustenbach ed., 2002) (explaining that weak versions of the Principle are unobjectionable). 
does not prescribe any particular regulatory measures, some commentators have argued that it is essentially vacuous - a "feeble addition[] to the regulatory landscape." 36 Sunstein agrees. He concludes that the Weak Precautionary Principle, while valid, is a mere "truism," so "banal" as to be hardly worth further scholarly exploration. ${ }^{37}$

Although Sunstein himself accepts the Weak Precautionary Principle, others have attacked the Principle in three decades of acrimonious debates, inside and outside the academy. Scholars have squared off over how the Weak Precautionary Principle should be implemented; whether it is consistent with quantitative risk assessment and cost-benefit analysis, or represents an alternate paradigm; and whether it actually animates U.S. law or has instead been eroded through unreasonably stringent "hard look" review and judicial demands for comprehensive administrative records. ${ }^{38}$ In Washington, there is a widespread perception that weak versions of the Precautionary Principle give extra "weight" to environmental factors in risk decision making and would lead to abandonment of "sound science" in favor of regulation based on speculation and supposition of various threats to the environment. Public statements to this effect are voluminous..$^{39}$ These debates over the meaning of precaution are, in essence, a proxy battle for much larger debates over how stringent government regulation should be, what kinds of margins of safety should be built into it, and when it should be deployed.

Many of these same debates carry over to the Strong Precautionary Principle as well. Yet while weak versions of the Precautionary Principle have dozens of advocates in the legal academy, few legal scholars have elaborated a defense of Strong Precaution. This perhaps reflects muddled definitions, as many scholars have advocated embracing the Precautionary Principle without defining which version of the Principle they

36. Edward Soule, Assessing the Precautionary Principle, 14 PUB. AFF. Q. 309, 315 (2000).

37. SUNSTEIN, supra note 12 , at 24 .

38. See Percival, supra note 22 , at 36-37 (arguing that "despite the regulatory statutes' commitment to preventative regulation," environmental law remains largely reactive, and regulation is rarely imposed until damage to public health has occurred).

39. See 150 CONG. REC. 23,369 (2004) (statement of Sen. Inhofe) ("[Global warming] alarmists often trot out a concept known as the precautionary principle-which is that it is better to be safe than sorry. But .... [t] he science of global warming is uncertain, the costs of capping our economy with carbon restriction are high, and even if the doomsayers were correct, it would do little to nothing to reduce the temperature increases."); GARY E. MARCHANT \& KENNETH L. MOSSMAN, ARBITRARY and Capricious: The Precautionary Principle in the European Union Courts 1 (2004) ("Perhaps the most common criticism of the precautionary principle ... is that it inherently ambiguous and arbitrary."); Lawrence A. Kogan, The Extra-WTO Precautionary Principle: One European "Fashion" Export the United States Can Do Without, 17 TEMP. POL. \& CIV. RTS. L. REV. 491, 506-07 (2008) (stating that the Precautionary Principle asks legislators "to evaluate public risks based on political, ethical, and/or social science concerns, rather than upon common-sense or hard, empirical, sound science"); Soule, supra note 36, at 313; PARTNERSHIP FOR SOUND SCIENCE IN ENVIRONMENTAL POlicy, PreCAutIonARY PRINCIPLE OVERVIEW 1, (n.d), http://cicc.org/jru/031306/PP_Overview.pdf (" $[T]$ he Precautionary Principle diverts the attention of regulators and resources from real issues to speculative concerns.... Implementing the Precautionary Principle can cause more harm than good..." (emphasis omitted)). 
mean. ${ }^{40}$ The lack of attention to Strong Precaution might also reflect that weaker versions of the Principle appear more "tame" or acceptable to policy makers. ${ }^{41}$

No doubt the Strong Precautionary Principle is a lightning rod. As I shall argue, however, it provides an important framework for protecting Americans from toxic chemicals and other hazards, and it deserves a sustained analysis of its merits.

\section{The Strong Precautionary Principle}

Both weak and strong versions of the Precautionary Principle emphasize anticipation of harm and taking preventive measures in the face of uncertainty, but there are some important differences between the two approaches. Whereas weak versions of the Precautionary Principle permit the government to regulate risks under conditions of scientific uncertainty, the Strong Precautionary Principle suggests that some precautionary regulation should be a default response to serious risks under conditions of scientific uncertainty. Such regulation could range from a blanket prohibition on a proposed technology or a dangerous activity to less aggressive defaults, such as use restrictions or warning requirements. ${ }^{42}$ Furthermore, whereas weak versions are primarily concerned with the timing of governmental decision making, the Strong Precautionary Principle explicitly places the burden on the private proponent of the riskcreating activity to overcome the default by proving that risks are acceptable or reasonable. ${ }^{43}$

As noted in the Introduction, I define the Strong Precautionary Principle as the view that: (1) regulation should presumptively be applied when an activity or product poses serious threats to human health or the environment, even if scientific uncertainty precludes a full understanding of the nature or extent of the threats; and (2) the burden of overcoming the presumption in favor of regulation lies with the proponent of the risk-creating activity or product.

40. The Treaty on the Functioning of the European Union is typical in this regard, as it declares that EU environmental policy "shall be based on the precautionary principle," without defining the Principle in the treaty. See TFEU art. 191. Partly to fill that gap, the European Commission has issued its own (caveated) interpretation of the meaning of the Precautionary Principle. See COMM'N OF the European CMtys., Communication From the Commission on the Precautionary PRINCIPLE (2000).

41. See Applegate, The Taming, supra note 22, at 23-24 (documenting progressively softer and less aggressive interpretations of the Precautionary Principle in risk regulation since the early 1990 s).

42. The precautionary measures that can be applied under the Principle will necessarily vary, depending on the magnitude of the expected risk and the strength of the scientific evidence. See infra Part II.

43. By emphasizing that precautionary measures "should be taken" in response to threats to human health or the environment, the Strong Precautionary Principle represents an affirmative call to action, whereas the Weak Precautionary Principle is phrased in the negative (scientific uncertainty should not be used as a reason for postponing cost-effective regulatory measures) and, therefore, can be seen as less demanding or less action-forcing. 
My definition roughly parallels the Wingspread Statement, a document on precaution adopted by a group of prominent physicians, scholars, and environmentalists in 1998.44 The Wingspread Statement was primarily directed at emerging toxic risks, such as endocrine-disrupting chemicals. Its language is broad, however, and it is often described in the literature as emblematic of the Strong Precautionary Principle: ${ }^{45}$

When an activity raises threats of harm to human health or the environment, precautionary measures should be taken even if some cause-and-effect relationships are not fully established scientifically. In this context the proponent of an activity, rather than the public, should bear the burden of proof. ${ }^{46}$

I do not adopt the Wingspread Statement as my own definition because it does not include the proviso that "threats" must be "serious." For the Principle to be workable, there must be some serious risk threshold for invoking precautionary measures and a shift in the burden of proof. Precautionary measures (such as bans, restrictions, or labeling and/or warning requirements) can be expensive and complex to implement, and they should not be invoked for trivial dangers, or for activities where there is no credible evidence of a risk. ${ }^{47}$

With that caveat in mind, the Strong Precautionary Principle, as I have defined it, clearly places a default "hold" on certain activities that may pose serious risks, until the proponent can prove that the activity can be conducted safely, or at least with acceptable risk. In this sense, the Principle establishes a "stop and think" mechanism under which the risk creator bears the burden both to quantify the risk and to disclose relevant risk data to regulators (such as accident probabilities, toxicity data, health studies, dispersal projections for release of toxic materials, etc.).

Looking at my definition of Strong Precaution, it is clear that some key issues, such as the degree of threat that will trigger burden shifting, the precise precautionary measures that should be taken, and how much information on risk the proponent must supply, are not specified in the Principle itself. The Principle's generality leads Cass Sunstein, Gary Marchant, and other critics to conclude that the Principle provides no guidance whatsoever. ${ }^{48}$

44. SUNSTEIN, supra note 12 , at 19.

45. See, e.g., Edward Soule, Morality \& Markets: The ETHICs of Government RegULATION 147 (2003).

46. Protecting Public Health \& the Environment, supra note 23 app. A, at 353-54 (quoting the Wingspread Statement on the Precautionary Principle). See also id. intro., at 7-9 (discussing the history of the Wingspread Conference).

47. There are many other formulations of the Strong Precautionary Principle in the literature, including some that suggest that any risk-producing activity must be halted until it is proven safe. These highly aggressive, zero-risk standards should be rejected, as I explain in Part II. These outliers need not deflect our attention from exploring versions of Strong Precaution that have some political viability. Defending the Strong Precautionary Principle does not mean aligning oneself with the most extreme, risk-intolerant formulations of it.

48. See, e.g., MARCHANT \& MOSSMAN, supra note 39, at 1; Sunstein, supra note 15, at 1003. 
Like any principle, however, Strong Precaution outlines a framework or stance toward decision making, not a meticulously detailed prescription for action. The details of regulatory design and the timing of response are determined through legislation, not the Principle itself. They will necessarily vary from one regulatory context to another. ${ }^{49} \mathrm{Leg}$ islation grounded in the Strong Precautionary Principle might specify, for example, that to commence with an activity or to introduce a product, the proponent must prove "no substantial risk" to human health. Or, the proponent might be required to prove that the benefits outweigh the risks, or that the activity will be conducted in accordance with predetermined safety standards. No serious analyst would contend that a one- or two-sentence principle is the total guidance that regulators need to manage complex health and environmental risks. ${ }^{50}$

Generality does not equate with vacuity, however. Strong Precaution is not an empty "truism." It creates a recognizable architecture establishing who carries the burden of proof on complex public health and environmental controversies.

The Principle can be compared to other similarly broad principles of U.S. government, such as due process or equal protection, whose meanings have been developed through repeated application in particular cases and controversies. Or, since I argue that the Principle need not be universally applied, the Principle can be compared to other, nonconstitutional principles that have provided loose guidance to successive administrations, such as the containment doctrine during the Cold War. The containment doctrine was broadly defined and was subject to multiple interpretations and bitter disagreements about its meaning. ${ }^{51}$ Its full

49. See Kysar, supra note 22, at 7 n.32 (2006) ("Important implementation issues then include: (1) the degree of credibility or seriousness of threat required in order to trigger the precautionary obligation; (2) the precise form that regulatory response should take; (3) and the manner in which the regulatory response should be revisited and revised over time.").

50. See Applegate, Climate Change, supra note 22, 171-72 (noting that the Rio Declaration required twenty-seven principles to outline a broad framework for sustainable development and that the Precautionary Principle is but one component of this framework).

51. The founding documents of the containment strategy, such as National Security Council Memorandum 68 (NSC 68), used broad and open-ended language to describe the kinds of U.S. responses that would be appropriate to counter Soviet power and expansionism. The meaning of containment, therefore, was left to a discursive process of interpretation and implementation that occurred over decades among the White House, Congress, the Pentagon, and other national security agencies. NSC 68 stated, in part:

For us the role of military power is to serve the national purpose by deterring an attack upon us while we seek by other means to create an environment in which our free society can flourish....

Our free society, confronted by a threat to its basic values, naturally will take such action, including the use of military force, as may be required to protect those values.... In the words of the Federalist (No. 28) "The means to be employed must be proportioned to the extent of the mischief." .. Our aim in applying force must be to compel the acceptance of terms consistent with our objectives, and our capabilities for the application of force should, therefore, within the limits of what we can sustain over the long pull, be congruent to the range of tasks which we may encounter.

Nat'l Sec. Council, a Report to the National Security Council by the Executive SECRETARY, NSC 68 (Apr. 14, 1950), reprinted in U.S. DEP'T OF STATE, PUB. No. 8887, 1 FOREIGN RELATIONS OF THE UNITED STATES 234, 244 (1950). 
scope was determined only through implementation in particular decisions and crises. ${ }^{52}$ Despite its generality, however, the containment doctrine provided a framework for action and helped to unite disparate factions of Congress, defense, and foreign policy agencies against the Soviet military threat. ${ }^{53}$ The Strong Precautionary Principle could serve a similar function by providing a framework for addressing serious environmental and public health threats.

One defining feature of the Strong Precautionary Principle is that it places a governmental entity in a role as a risk gatekeeper. Implicit in the Principle is the idea that there must be a "decider" who will determine whether the proponent of the activity has met its burden of proof on safety. ${ }^{54}$ The preventive thrust of Strong Precaution further implies that this review of risks should occur before the activity commences or the potentially risky product reaches the market. Critics contend that the Principle is "anti-scientific"55 or will devolve into regulation based on speculation, ${ }^{56}$ but the Principle is fully consistent with scientific risk assessment techniques. Indeed, scientifically sound risk assessment is crucial to identify which risks are "serious" and worthy of regulatory attention. The Principle encourages conducting that risk assessment, where possible, on an ex ante, premarket basis, rather than in a reactive posture in response to harm that has already occurred.

This comparatively aggressive role for government to police private sector activity, or to determine ex ante which products can and cannot be marketed, has received intense criticism, especially from the right. ${ }^{57}$ If the Weak Precautionary Principle implies a relatively libertarian view of the world, in which regulators are empowered (but not required) to intervene in the marketplace to address externalities - "threats of serious or irreversible damage" to the environment ${ }^{58}$-then the Strong Precautionary Principle implies a more vigorous role for government to deter-

52. See Roger S. Whitcomb, The COld War In Retrospect: The Formative Years 87-88 (1998).

53. See id. at 93-101.

54. Literature on the Strong Precautionary Principle has rarely addressed this core issue of who should decide whether the burden of proof has been met. The Lowell Statement on Science and Precautionary Principle, for example, states that "responsibility" should be placed on "originators of potentially dangerous activities to thoroughly study and minimize risks, and to evaluate and choose the safest alternatives to meet a particular need, with independent review." Tickner et al., supra note 28, at 489 (emphasis added). The entity that should conduct that independent review is not specified, however. See also Protecting PUBLic HEALTH \& THE EnVironmENT, supra note 23 intro., at 8 (stating that the "proponent of an activity ... should bear the burden of proof" but not identifying who will judge whether the proponent has met that burden).

55. Sallie Baliunas, Warming Up to the Truth: The Real Story About Climate Change, HERITAGE FOUND. (Aug. 22, 2002), available at http://www.heritage.org/research/lecture/the-realstory-about-climate-change.

56. SUNSTEIN, supra note 12; John D. Graham, The Perils of the Precautionary Principle: Lessons from the American and European Experience (Oct. 20, 2003), in HERITAGE LeCTURES, Jan. 15, 2004 , at $1-4$.

57. See, e.g., Adler, supra note 18 , at 174 ; Graham, supra note 56, at 1-4.

58. The Rio Declaration on Environment and Development, supra note 30, at 879. 
mine, ex ante, whether certain products or activities should be prohibited in the marketplace, given their health and environmental risks. Below, I respond to the criticism that Strong Precaution is overly bureaucratic or stifling of economic freedom. But for present purposes, the key point is simply to recognize the gatekeeping role of government under the Principle. In practice, Strong Precaution is usually operationalized through a governmental licensing, permitting, or preapproval system. In these contexts, the private proponent bears both the burden of production (researching the nature and extent of risks and making such evidence available for governmental review) and the burden of persuasion (demonstrating to the decision maker that specific statutory or regulatory safety standards have been met).

\section{B. The Salutary Signals of Strong Precaution}

In a 1999 article, Ronald Bailey, a libertarian science writer, lampooned the Strong Precautionary Principle, arguing that the Principle warps the "proverbial wisdom" of "look before you leap." 59 The Principle, he wrote facetiously, commands that citizens justify every leap in order to receive their "leaping license" from a "Federal Leaping Commission." ${ }^{60}$ Bailey charged:

In effect, before you or anybody else can leap, you will not only have to look beforehand in the prescribed manner, you will have to prove that if you leap, you won't be hurt, nor will any other living thing be hurt, now and for all time. And if you can't prove all of that, the commission will refuse to grant you a leaping license. ${ }^{61}$

This parody is amusing, yet it completely ignores why Strong Precaution is fully justifiable in some regulatory contexts, including chemical regulation.

Strong Precaution sends salutary signals to risk creators: it compels them to research the risks of their activities and sends an unmistakable message that we will not wait until damage is done before requiring some investigation and justification of the potential hazards. It ensures that the public is informed about, and has a say in, the deployment of technologies that may have serious public health impacts.

While more decentralized legal mechanisms, such as the tort system or contractual bargaining, may be appropriate to address identifiable risks affecting a small number of parties, these approaches are usually inadequate to address diffuse harm affecting whole communities, or harms with complex chains of causation. ${ }^{62}$ A Strong Precautionary framework,

59. Ronald Bailey, Precautionary Tale, REAson, Apr. 1999, at 37, 37.

60. Id at 37 .

61. Id. at $37-38$.

62. See Steven Shavell, Liability for Harm Versus Regulation of Safety, 13 J. LEGAL STUD. 357 (1984) (analyzing shortcomings of tort liability for addressing certain types of harms, including diffuse 
in contrast, makes sense where a risk creator's "leap" might cause widespread, diffuse harm to others (consider mercury pollution from a power plant or a manufacturer's decision to use endocrine-disrupting chemicals in the plastics for toys). The framework is also well suited for preventing ecosystem harm where responding to damage after the fact has serious drawbacks (consider the lax governmental oversight that contributed to the 2010 Deepwater Horizon Oil Spill).$^{63}$

Serious externalities turn private choice into public risks. If ex post tort remedies or ex post regulatory interventions are likely to be inadequate in the event that damage does occur, then it becomes reasonable to ask the "leaper" to justify why that activity should take place and to place some limits upon it, before potential harm occurs. ${ }^{64}$ A likely prospect of ex post legal failure, in other words, enhances the desirability of ex ante regulatory gatekeeping.

In the context of toxic chemicals, "leaping" (introducing untested chemicals into commerce) may lead to harm that is nonconsensual or unknown to the injured party, to diffuse low-level harms, or to serious harm that may occur decades after the "leap" occurs. ${ }^{65}$ Given that diffuse harm from chemicals is poorly addressed through tort suits or postmarket regulatory interventions, requiring a chemical manufacturer to undertake ex ante investigation and justification of risks, far from being excessive or extreme, is sensible public policy.

Strong Precaution establishes this risk gatekeeping mechanism. It offers both a procedural tool for incentivizing risk research and substantive default rules for protecting public health.

Procedurally, the Principle acts as an information-forcing device. It provides a profit motive for firms to undertake research on the health and environmental risks of their own products and activities. ${ }^{66}$ Bearing the burden of proof, firms will have a keen interest in developing the risk

harms and harms where the tortfeasor may escape full internalization of the harm because it is judgment proof).

63. NAT'L COMM'N ON THE BP DEEPWATER HORIZON OIL SPILl \& OFFSHORE DRILling, DeEP WATER: THE GULF OIL DISASTER AND THE FUTURE OF OFFSHORE DRILLING 77-85 (2011) (detailing ethical lapses, mismanagement, and lax oversight in the Department of Interior and criticizing the categorical exemptions of site-specific Gulf of Mexico drilling plans from the review procedures of the National Environmental Policy Act).

64. See DOUglas A. KYSAR, REgUlating FROM NOWHERE: ENVIRONMENTAL LAW AND THE SEARCH FOR OBJECTIVITY 9 (2010) ("Proponents of the precautionary approach . . emphasize the limits of human knowledge and the frequency of unpleasant surprises from technology and industrial development; thus, they advocate an ex-ante governmental stance of precaution whenever a proposed activity meets some threshold possibility of causing severe harm to human health or the environment.").

65. See Noah Sachs, Blocked Pathways: Potential Legal Responses to Endocrine Disrupting Chemicals, 24 COLUM. J. ENVTL. L. 289 (1999) (detailing obstacles to private tort litigation over chemical exposures).

66. The informational benefits of the Precautionary Principle have been widely noted in the literature. See Applegate, supra note 33; Carl F. Cranor, Asymmetric Information, the Precautionary Principle, and Burdens of Proof, in Protecting Public Health \& THE EnVIRonment, supra note 23 , at $74,81-82$. 
assessment data that will facilitate approval by government regulators (consider the investment that drug manufacturers make in clinical trials and in New Drug Applications to the Food and Drug Administration). The Principle flips the perverse incentives that occur under a regulatory regime with a governmental burden of proof, in which regulated firms stand to gain by not developing, or by obfuscating, important risk assessment data.

With some exceptions, a governmental burden of proof is the norm in U.S. environmental and public health law. ${ }^{67}$ As Wendy Wagner has observed, the governmental burden of proof under TSCA has encouraged chemical manufacturers to maintain "strategic ignorance" by not developing toxicity data on their own products. ${ }^{68}$ TSCA does not establish routine risk assessment requirements for chemicals, but instead authorizes EPA to order risk assessments on a case-by-case basis (each EPA test rule is a major rulemaking process, requiring two to ten years for the agency to finalize). ${ }^{69}$ As a result, thirty-five years after TSCA's enactment, we have basic toxicity data for only a few thousand of the 84,000 chemicals that have been introduced into commerce in the United States. ${ }^{70}$ The threat of tort liability does not cure this deficiency of regulatory law. ${ }^{71}$ In fact, the tort system likely reinforces strategic ignorance, as it provides an incentive for chemical manufacturers to avoid any research on product hazards that could trigger ex post liability. ${ }^{72}$

A regulatory regime that combines a high burden of proof on an agency with a data-starved informational environment is likely to lead to regulatory paralysis. This has been the story of TSCA since its enactment.

The Strong Precautionary Principle, in contrast, recognizes that the supply of risk assessment data on a given product or activity is not exogenous to the regulatory system. Incentives built into the regulatory system, rather, help determine whether firms will undertake basic research on the health and environmental effects of their products and ac-

67. See, e.g., Administrative Procedure Act, 5 U.S.C. \$ 556(d) (2006) ("Except as otherwise provided by statute, the proponent of a rule or order has the burden of proof.").

68. Wagner, supra note 2, at 1685 .

69. GAO, OPTIONS EXIST, supra note 2, at 19-26.

70. This "data drought" has many causes, including that: (1) TSCA provides no mandate for routine toxicity testing for most chemicals on the market, (2) the statute in practice requires EPA to assemble substantial information on the risks of a chemical just to issue an order to require testing, and (3) industry has frequently litigated over the few testing orders that the EPA has issued. See Sachs, supra note 2, at 1827-28 (outlining features of TSCA that limit data supply).

71. Dana, supra note 27 , at 83 .

72. See id. (explaining that "rational, profit-maximizing corporations and other actors will not invest in testing and monitoring" under certain conditions, including "when particular products pose theoretical risks but not empirically-established ones; when any adverse effects would likely occur only in the relatively distant future; and when the link between the product and any distant adverse effects could well escape notice, or at least be difficult to establish as a matter of 'but for' causation"). 
tivities. $^{73}$ As Jim Salzman and Doug Kysar observed, shifting the burden of proof "works to counterbalance certain perceived structural asymmetries of the unregulated market" and "actively deploy[s] private actors in service of the public's informational needs." 74

European Union (EU) chemical legislation, called Registration, Evaluation, Authorisation and Restriction of Chemicals (REACH), ${ }^{75}$ provides one prominent example of the information-forcing incentives of the Strong Precautionary Principle. In REACH, the EU implemented the concept of "No Data, No Market," under which manufacturers and importers are obligated to submit a basic toxicity data set for any chemical produced or imported in the EU in a volume of ten tons or more. ${ }^{76}$ Unlike TSCA, REACH is a true market-access regulation. The submission of the data set is made a precondition of access to the $€ 537$ billion European chemical market. ${ }^{77}$ By rewarding knowledge and making chemical manufacturers responsible for data production, $\mathrm{REACH}$ is helping to end the data drought that has plagued European chemical regulation since the early 1980 s. $^{78}$ U.S. chemical firms doing business in Europe are already subject to REACH, and as I explained in a previous article, the implementation of REACH in Europe is likely to undermine objections of U.S. chemical manufacturers that routine toxicity testing is too expensive or cumbersome. ${ }^{79}$

While providing an important framework for gathering data, the Strong Precautionary Principle should be viewed as more than an informational tool. In chemical regulation, a strategy of "filling" data gaps with more research can only take us so far. ${ }^{80}$ Uncertainty about key is-

73. Kysar, supra note 22, at 28 ("[P]roponents of the [Precautionary Principle] recognize that uncertainty itself is a subject of power, influence, and control .... Thus, the content of scientific knowledge and the manner of its production are not treated exogenously by the [Precautionary Principle], but instead are made a central focus of the regulatory program.").

74. Douglas A. Kysar \& James Salzman, Making Sense of Information for Environmental Protection, 86 TEX. L. REV. 1347, 1351-52 (2008).

75. Commission Regulation 1907/2006, 2006 O.J. (L 396) 1 (EC) [hereinafter REACH].

76. Sachs, supra note 2, at 1834-35.

77. Id. at 1835 . The preamble to $\mathrm{REACH}$ states that the regulation "is based on the principle that it is for manufacturers, importers and downstream users to ensure that they manufacture, place on the market or use such substances that do not adversely affect human health or the environment." REACH, supra note 75 , at 47.

78. Only seventy chemical risk assessments were required by government regulators in the prior thirty years, out of a universe of more than 30,000 chemicals produced in quantities greater than one ton. Sachs, supra note 2, at 1833-34.

79. See id. at 1862-67 (analyzing the extraterritorial impacts of REACH).

80. John Applegate's distinction between "filling strategies" and "bridging strategies" to overcome data gaps in chemical regulation has been an important contribution to the debate over TSCA reform. See John S. Applegate, Bridging the Data Gap: Balancing the Supply and Demand for Chemical Information, 86 TEX. L. REV. 1365 (2008). Applegate argues that "filling strategies," involving more research, often have diminishing returns due to the time and expense of chemical testing and residual scientific uncertainty about the extent of risk even when testing is conducted. Id. at 1385-89. "Bridging strategies," on the other hand, are designed to "bridge" the data gap by reducing the overall regulatory demand for information. Id. at 1395-1406. Bridging strategies include technology standards, shifts in the burden of proof, and incentives for safer substitute chemicals. Id. See also David E. Adelman, A Cautiously Pessimistic Appraisal of Trends in Toxics Regulation, 32 WASH U. J.L. \& 
sues, such as low-dose effects of chemicals, may not be resolvable even through extensive testing. The Strong Precautionary Principle also helps to "bridge" data gaps by altering default decision rules for how the government should respond when scientific uncertainty prevents a complete assessment of environmental or health risks.

The primary goal under Strong Precaution is to avoid Type II (false negative) decision errors. A risk regulatory regime grounded in Strong Precaution would aim to avoid the false conclusion that there is low risk for products and activities that in fact pose grave risks. Through shifting the burden of proof, if the proponent can develop only scant information on the nature or extent of risk, Strong Precaution applies a default prohibition (or at least restriction) on the activity or product. Strong Precaution provides a window of opportunity for advance review of risks, and in implementing the Principle in a particular statute, legislators are making a decision to err on the side of caution when there are conflicting studies or insufficient information to characterize risks accurately. ${ }^{81}$

In contrast, many U.S. regulatory regimes, including TSCA, place a premium on avoidance of Type I (false positive) errors. They start with the assumption that risks are zero, unless a government agency gathers data and affirmatively proves the presence of substantial risk to trigger regulation. Under TSCA, EPA must meet this burden-proving "unreasonable risk" from a chemical under Section 6-under searching standards of judicial review, and the agency has succeeded in restricting only five chemicals under that standard in the thirty-five year history of the Act. ${ }^{82}$ This ostensible regulatory authority of the EPA has been crippled in practice since 1991, when EPA's regulation banning most uses of asbestos was struck down by the U.S. Court of Appeals for the Fifth Circuit in Corrosion Proof Fittings v. E.P.A. ${ }^{83}$ Since that case, EPA has not imposed any restrictions on chemicals already on the market under Section 6, and Corrosion Proof Fittings is widely viewed as the death knell for EPA's practical ability to restrict dangerous substances under TSCA. ${ }^{84}$

Regulatory regimes designed to avoid Type I errors, such as TSCCA, are not value neutral. They reflect an implicit assumption that the cur-

POL'Y 377, 381 (2010) ("[T]oxics regulation should avoid the deep epistemic gaps to the extent that it can.").

81. See Hansson, supra note 23, at 227 (arguing that in implementing a burden shift in chemical regulation, where there are "diverging but scientifically sound interpretations of toxicological data, precedence should be given to the interpretations that support the most pessimistic predictions with respect to human health").

82. GAO, OPTIONS EXIST, supra note 2, at 18.

83. 947 F.2d 1201 (5th Cir. 1991). One reason that the court rejected the asbestos ban was because EPA had not performed a comprehensive cost-benefit analysis for intermediate measures short of a complete ban under the complex procedures of the statute. Id. at 1230 .

84. Dan Fagin \& Marianne Lavelle, Toxic Deception: How the Chemical industry MANipulates SCIENCE, Bends THE LAW AND ENDANGERS YOuR HEALTH 138 (1996); Robert V. Percival, Responding to Environmental Risk: A Pluralistic Perspective, 14 PACE ENVTL. L. REV. 513 (1997); Sachs, supra note 65, at 324. 
rent economic order and mix of products in the marketplace is to be particularly valued and should not be disturbed absent a very high threshold showing by the government. ${ }^{85}$ The Strong Precautionary Principle, on the other hand, requires justification from private actors for why products or activities that may cause serious harm to the public should be allowed on the market. It thereby highlights the moral obligations of firms that profit from activities that could cause widespread public harm. Indeed, the Principle reminds both the regulator and the regulated party that risk regulatory decisions carry "distinctive moral weight and responsibility." 86

Each default decision rule has its potential drawbacks. Legislation designed to avoid Type I errors raises the possibility of regulation that comes "too late" or that is underprotective, responding to serious harm only after it occurs. Statutes grounded in Strong Precaution raise the possibility of regulation that is "too early" or that aggressively responds to risks that may later turn out to be less severe than initially believed. But some default decision rule must be chosen, and we should not dismiss the default presumptions of Strong Precaution out of hand. The most pressing question, rather, is deciding which default decision rules make sense in particular areas of law.

In chemical regulation, it has become clear that Congress erred on the side of unsafety, or as Wendy Wagner put it, "unprecaution." 87 As I explain in Part III, implementing the Strong Precautionary Principle would redress many of the historic flaws in TSCA. The question is, will Congress adopt this framework for chemical risk management, given how the critics have tarnished it?

\section{Rescuing the Strong Precautionary Principle FROM ITS CRITICS}

The Strong Precautionary Principle has become a punching bag for many scholars of risk regulation. Cass Sunstein and other prominent scholars have unsparingly attacked it, and lacking many defenders, the Principle's reputation has been battered.

In this Part, I respond to these critiques. My rebuttal here is qualified. I fully concede that the Strong Precautionary Principle cannot be a universally applicable approach to all health and environmental dangers that society faces. But it can serve as the platform for protective risk decision making in discrete areas of law, including chemical regulation. By caricaturing the Principle as extreme and dismissing it out of hand as un-

85. Cranor, supra note 23 , at 271 .

86. Kysar, supra note 22, at 12.

87. Wendy E. Wagner, The Precautionary Principle and Chemical Regulation in the U.S., 6 HUM. \& ECOLOGICAL RISK ASSESSMENT 459, 468 (2000) (arguing that TSCA reflects an "unprecautionary principle"). 
workable, the Principle's detractors have overlooked both its utility and the myriad examples where it already operates successfully in U.S. law.

\section{A. The Critics' Complaints}

The critics share some common objections. They often maintain that the Principle is extreme, inflexible, anti-science, anti-growth, or antitechnology ${ }^{88}$ Because Strong Precaution shifts the burden of proof on safety, critics allege that its implementation would prevent promising new technologies from getting off the ground, especially in emerging fields with a high degree of uncertainty about risks. ${ }^{89}$ Sunstein claims that the Strong Precautionary Principle would "eliminate technologies and strategies that make human lives easier, more convenient, healthier, and longer." 90 John Graham names the internal combustion engine, electricity, plastics, and the Internet as examples of technologies that would have been prohibited.91 Harvey Miller and Gregory Conko further charge that "[i]f the precautionary principle had been applied decades ago to innovations such as polio vaccines and antibiotics, ... that precaution would have come at the expense of millions of lives lost to infectious diseases." 92

The claim that Strong Precaution is antithetical to technological progress is closely related to another view in the critical literature: Strong Precaution requires that manufacturers prove "zero risk" or "absolute safety" for an activity to proceed. ${ }^{93}$ These, of course, are impossible standards to meet (and the Strong Precautionary Principle, as I and others have defined it, does not impose them). Other critics suggest that the Principle will be applied on the mere "conjecture" 94 or "speculation" a threat to health or the environment, suppressing important technologies without any scientific basis. In addition, because of the strong government role and the shift in the burden of proof, critics have argued that Strong Precaution is overly statist; its "guilty-until-proven-innocent" approach to addressing risk is allegedly contrary to U.S. values. ${ }^{96}$

88. See, e.g., Julian Morris, Defining the Precautionary Principle, in RETHINKING RISK AND THE Precautionary PRINCIPLe 1 (Julian Morris ed., 2000); Frank B. Cross, Paradoxical Perils of the Precautionary Principle, 53 WASH. \& LEE L. REV. 851 (1996); Graham, supra note 24.

89. See, e.g., Graham, supra note 24.

90. SUNSTEIN, supra note 12 , at 25.

91. Graham, supra note 56 , at 3 .

92. Henry I. Miller \& Gregory Conko, The Science of Biotechnology Meets the Politics of Global Regulation, ISSUES IN SCI. \& TECH. ONLINE (2000), http://www.nap.edu/issues/17.1/miller.htm.

93. See, e.g., Kogan, supra note 39, at 601-03.

94. See Miller \& Conko, supra note 92.

95. See Cass R. Sunstein, The Precautionary Principle As a Basis for Decision Making, 2 ECONOMISTS' VOICE 1, 5 (2005) (claiming that the Precautionary Principle "attempt[s] to prevent even speculative harm").

96. See Bailey, supra note 59, at 37; Kogan, supra note 39, at 601-03 (contrasting the Precautionary Principle with the "founding principles of our society, chief among them economic and political freedom and the rule of law"); Miller \& Conko, supra note 92. 
Cass Sunstein, the leading U.S. critic of the Strong Precautionary Principle, claims that the Principle is, ultimately, paralyzing as an approach to risk decision making. ${ }^{97}$ If the Strong Precautionary Principle presumptively requires regulation of activities that present serious threats to health, safety, or the environment, then, according to Sunstein, the Principle will paralyze decision makers because threats may be created both by regulatory inaction and by regulatory action. ${ }^{98}$

This "paralysis" critique begins from the proposition that regulation itself has costs and potential risks. For instance, introduction of genetically modified crops may harm ecosystems, but harm may also occur (from increased hunger or more widespread pesticide use) if genetically modified crops are prohibited.99 With respect to drug approvals, Sunstein notes that stringent Food and Drug Administration (FDA) review requirements for new drugs may block introduction of dangerous medications, but the delay involved in FDA review (so-called "drug lag") means that life-saving drugs may not reach patients who need them.100 Sunstein questions: "Is it 'precautionary' to require extensive premarketing testing, or to do the opposite?"101 The Strong Precautionary Principle allegedly provides no guidance. According to Sunstein, the Principle "forbids all courses of action, including regulation. It bans the very steps that it requires." 102

Given the presence of these risk-risk tradeoffs, Sunstein maintains, a principle that calls generally for caution in the face of risk, or that calls for shifting the burden of proof in response to serious threats to human health or the environment, is logically incoherent. Strong Precaution only seems appealing as an approach to risk because we naturally focus our attention on certain novel "target" risks (such as genetically modified foods or a chemical recently in the news, such as Bisphenol-A) and ignore both the opportunity costs of regulation and the risks presented by the status quo. ${ }^{103}$ The way out of these decision-making dilemmas, Sun-

97. See SUNSTEIN, supra note 12, at 14-15.

98. Id.

99. Id. at 31 .

100. Id. at 29

101. Id. In another example, Sunstein notes that many chemical agents may be carcinogenic at very low levels, while others may be beneficial at very low levels even if harmful at high levels (the socalled "hormesis" effect). Id. at 30-31. Therefore, the "simultaneous possibility of benefits at low levels and of harms at low levels makes the Precautionary Principle paralyzing." Id.

102. Id. at 26.

103. Sunstein argues that five different cognitive biases operate to make the Strong Precautionary Principle appear functional: (1) individuals focus on salient risks that come to mind from media reports or recent memory, and they ignore less visible risks; (2) probability neglect leads people to concentrate on worst-case outcomes, even if they are highly improbable; (3) loss aversion causes people to avoid changes from the status quo, even if the status quo poses its own risks; (4) a widespread belief that nature is benign makes human-created risks seem particularly suspect; and (5) system neglect prevents people from appreciating opportunity costs and the substitute risks that may arise when a particular technology or product is restricted. See id. at 36-49; Sunstein, supra note 15, at 1011 (arguing that the Principle's "puzzling appeal" reflects its dependence on cognitive biases). 
stein maintains, is comprehensive cost-benefit analysis, ${ }^{104}$ or, as John Graham and Jonathan Wiener advocate, "risk tradeoff analysis." 105 Through careful quantitative analysis, critics suggest, regulators will be able to assess and compare the risks that would be created by different decision-making paths. ${ }^{106}$ Once these risks are identified, regulators can then choose the most cost-effective risk-reducing interventions.

\section{B. Countering the Critics}

To defend use of the Strong Precautionary Principle in regulatory law, I make three principal claims. First, I demonstrate that Strong Precaution already operates successfully in U.S. law, undermining critics' arguments that the Principle is somehow inherently unworkable or paralyzing. Second, I show that the critics' charge of extremism is overheated. The Principle does not require prohibiting all risky activities, and in fact it provides flexibility for policy makers to determine how much risk will be tolerable or acceptable in a given area of law, as well as flexibility to determine proportionate regulatory responses. Finally, I show that the critique that Strong Precaution is "paralyzing" because of risk-risk tradeoffs is overstated, especially against the backdrop of its practical implementation in U.S. law. Properly implemented, the Principle allows regulators to consider tradeoffs and alternatives. It commands neither extreme regulation nor abdication of judgment.

\section{Strong Precaution in Existing Law}

Critics often paint Strong Precaution as a new kid on the block, a yet-to-be-tried alternative to cost-benefit analysis, or an exotic import from Europe that has not been embraced in the United States. ${ }^{107}$ These attempts at delegitimization fail to recognize that the Strong Precautionary Principle already operates successfully in U.S. law. From Capitol Hill to state houses, legislators have frequently (and sensibly) turned to ex ante gatekeeping mechanisms to protect public health and the environment against serious risk.

The FDA's review process for new drugs is a prime example. Under the Federal Food, Drug, and Cosmetic Act, ${ }^{108}$ all substances meeting

104. SUNSTEIN, supra note 12, at 129 (cost-benefit analysis gives people "a more accurate sense of the actual harms against which protection is sought" and provides "a clearer sense of the stakes").

105. GRAHAM \& WIENER, supra note 18, at 19-22. Graham and Wiener describe risk tradeoff analysis as a three-part process that identifies tradeoffs that might result from an intervention, weighs the comparative importance of target risks and countervailing risks, and analyzes the possibility of "risk-superior" moves that might result in overall risk reduction. Id.

106. Sunstein, supra note 95 , at 6 ("We do not believe there is any principled way of making policy decisions without making the best possible effort to balance all the relevant costs of a policy against the benefits.").

107. See, e.g., Kogan, supra note 39, at 493.

108. Federal Food, Drug, and Cosmetic Act (FFDCA), 21 U.S.C. \$\$ 301-399 (2006). The FFDCA was enacted in 1938 and was substantially amended in 1962 to require the affirmative approv- 
the definition of a drug ${ }^{109}$ are presumptively banned from sale in the United States, unless the manufacturer produces relevant data on risks, side effects, and efficacy; conducts clinical trials; and receives affirmative FDA approval for sale. ${ }^{110}$ In this system, the FDA stands in the exact gatekeeping role called for by the Strong Precautionary Principle. Indeed, the FDA's new drug review system can be viewed as a particularly potent form of Strong Precaution, because the precautionary measure implemented as a response to serious threats to human health from untested drugs is a complete prohibition. That prohibition, backed by criminal penalties, ${ }^{111}$ remains in place (without any cost-benefit analysis) until the drug manufacturer can overcome the default and carry its burden of proof on safety and efficacy. ${ }^{112}$

Belying the argument that a gatekeeping role for government is inherently anti-science or anti-technology, the United States has maintained this FDA review process for decades while also developing the most innovative and profitable pharmaceutical industry in the world. As noted above, some critics point to antibiotics as the leading example of a useful product that would have been squelched if the United States had embraced Strong Precaution decades ago. ${ }^{113}$ But pharmaceutical manufacturers have developed life-saving antibiotics since the 1940s and will continue to do so, within a regulatory system that reflects Strong Precaution. ${ }^{114}$ Allocation of the burden of proof to drug manufacturers has neither extinguished the market for, nor the supply of, life-saving antibiotics.

The EPA's registration system for pesticides is another example of a Strong Precautionary approach to risk regulation. Under the Federal Insecticide, Fungicide, and Rodenticide Act (FIFRA), ${ }^{115}$ a pesticide manufacturer carries both the burden of production (compiling data on health and environmental effects of pesticides proposed for registration) and the burden of persuasion, showing that the pesticide complies with specific statutory standards, including that "it will perform its intended

al of the FDA before a new drug could be marketed. Prior to 1962, new drug applications were deemed approved unless a contrary order was issued. See USV Pharm. Corp. v. Weinberger, 412 U.S. 655 (1962).

109. See 21 U.S.C. § 321(g) (definition of "drug"); Id. \& 321(p) (definition of "new drug").

110. See id. \& 355(a) (prohibiting the sale of new drugs without FDA approval); Id. § 355(b)-(d) (describing the application and approval process).

111. Id. $\S 333(\mathrm{~b})$ ("[A]ny person who violates [the FFDCA] by . . knowingly selling, purchasing, or trading a drug ... shall be imprisoned for not more than 10 years or fined not more than $\$ 250,000$, or both.").

112. See id. \& 355 .

113. See supra note 92 and accompanying text.

114. It was the unregulated introduction of an antibiotic, causing widespread illness in the $1930 \mathrm{~s}$, which led to public outcry in favor of a premarket government review system. The purported antibiotic was called "Elixir Sulfanilamide," and more than one hundred people were poisoned by it in Tennessee before the FFDCA was enacted. See Richard A. Merrill, The Architecture of Government Regulation of Medical Products, 82 VA. L. REV. 1753, 1761-64 (1996) (describing the origins of the FFDCA).

115. Federal Insecticide, Fungicide, and Rodenticide Act (FIFRA), 7 U.S.C. $§ 136$ et seq. (2006). 
function without unreasonable adverse effects on the environment."116 EPA's role is to review the submitted risk data, determine whether the applicant has met the statutory criteria, and if so, approve labeling language and any use restrictions. ${ }^{117}$ The regulatory default, in advance of the pesticide manufacturer meeting its burden of proof, is to prohibit the introduction of the new pesticide. ${ }^{18}$

The rationale for EPA preapproval for pesticides and FDA preapproval for new drugs is similar: to prevent serious harm by requiring risk assessment, data disclosure, and agency review of risks before the product is placed into widespread circulation. In arguing for a shift in the burden of proof under TSCA, I am suggesting aligning chemical regulation more closely with these two older models of risk regulation.

John Applegate, who has written extensively on the role of the Precautionary Principle in risk regulation, has argued that FIFRA is the only example of a true burden-shifting statute in U.S. environmental law. ${ }^{119}$ But far more examples can be identified if we broaden the lens beyond statutes that license particular products to statutes that regulate environmentally hazardous activities. Strong Precaution is currently being applied not just in a few federal regulatory programs, but pervasively, in thousands of local, state, and federal permitting and licensing programs. From special use permits in local zoning laws to air emissions permits, water pollutant discharge permits, and nuclear power plant licenses, legislatures routinely establish regulatory regimes that contain a prohibition on engaging in an activity that may pose serious threats to human health or the environment. Such programs prohibit, on an ex ante basis, a class of activities suspected of posing potential risks, without any consideration of the economic benefits from individual activities within the class. The prohibition is overcome only when the proponent has applied for permission, researched and disclosed relevant risk data, met statutory standards, and received affirmative approval from a governmental entity.

The Clean Air Act, for example, prohibits operation of an entire class of industrial facilities and electric generating plants ("major sources"), until the facility obtains a permit from federal or state regulatory authorities. ${ }^{120}$ The operator of the source has the burden of demonstrating, through its own computer modeling, that the emissions from the

116. Id. § $136 \mathrm{a}(\mathrm{c})(5)(2006)$.

117. See U.S. Envtl. Prot. Agency, Pesticides, Regulating Pesticides, http:/www. epa.gov/pesticides/regulating/index.htm ("EPA must first ensure that the pesticide... can be used with a reasonable certainty of no harm to human health and without posing unreasonable risks to the environment. To make such determinations, EPA requires more than 100 different scientific studies and tests from applicants.").

118. See 7 U.S.C. $\$ 136$ a(a) ("Except as provided by this [Act], no person in any State may distribute or sell to any person any pesticide that is not registered under this [Act].").

119. See Applegate, supra note 33, at 430 ("With the notable exception of FIFRA, the burden of proving the existence and magnitude of an environmental risk is uniformly placed on the agency seeking to impose restrictions.").

120. 42 U.S.C. $\$ 7661 \mathrm{a}(\mathrm{a})$ (2006). 
source will not cause violations of the health-based National Ambient Air Quality Standards ${ }^{121}$ and other statutory requirements. In toxics regulation, the Resource Conservation and Recovery Act prohibits operation of any hazardous waste transport, storage, or disposal facility without a permit. ${ }^{122}$ Years of problems with responding to hazardous waste spills after the fact prompted Congress, in 1976, to turn to this ex ante licensing mechanism to ensure that operators are qualified, have adequate insurance, and undertake proper safety precautions. ${ }^{123}$

Strong Precaution's critics have rarely recognized such permitting and licensing programs as examples of the Principle's longstanding influence in U.S. law. ${ }^{124}$ Instead, critics such as John Graham treat the Principle as a novel, untested technique that would, if implemented, divert "the energies of regulators and the regulated community" from "known or plausible hazards to speculative and ill-founded ones." 125 But the nation's historic reliance on the Principle to protect important public values belies this assertion.

Critics are overlooking that the Principle can provide a workable accommodation between the needs of industry and the need to ensure harm prevention and adherence to ecological limits. Specifically, putting government in a risk gatekeeping role serves several important purposes, including:

- Ensuring that the applicant is competent to engage in the activity and has the required expertise and resources;

- Regulating the location of potentially risky activities and ensuring that they occur in places where risks to the public are minimized;

- Ensuring that activities presenting serious threats to public health or the environment can be prohibited (or have safety precautions placed on them) before harm occurs;

- Ensuring, through establishing a uniform review process for every applicant, that the cumulative amount of a risky activity

121. See id. $\$ 7409$ (2006) (requiring EPA to set National Ambient Air Quality Standards (NAAQS) at a level that "protect[s] the public health" with "an adequate margin of safety"). In 2001, the Supreme Court affirmed that the NAAQS are health-based standards that EPA must establish without reliance on cost-benefit analysis. Whitman v. Am. Trucking Ass'n, Inc., 531 U.S. 457, 471 (2001).

122. 42 U.S.C. $\$ 6925(2006)$.

123. See id. $\$ \$ 6901(\mathrm{~b})(6), 6924(\mathrm{a})(6)$.

124. To be sure, there are also many examples of U.S. regulatory regimes grounded in precautionary standard setting without a switch in the burden of proof, such as the initial establishment of the NAAQS under the Clean Air Act. Id. $\S 7409$. There are also many examples of ex post interventions, such as the product recall authority of the Consumer Product Safety Commission or the authority of the EPA to issue removal orders in response to hazardous substance releases. See 15 U.S.C. \& 2064(b) (2006); 42 U.S.C. $\$ 9606$ (a) (2006). Taken as a whole, the U.S. approach to addressing health and environmental risks is a complex pastiche of different kinds of ex ante and ex post interventions.

125. Graham, supra note 56 , at 5 . 
does not exceed limits that would be damaging to the environment or human health; and

- Minimizing risks while further research is conducted and making that research the responsibility of firms that will benefit the most from the activity.

I am not trying to defend every permitting and licensing scheme, of course. Government permitting programs can be burdensome and prone to political favoritism and rent-seeking behavior. They are often complex. If inadequately funded and staffed, a governmental review may be no more than a fig leaf of risk management (witness the Deepwater Horizon Oil Spill and the lax oversight of the Minerals Management Service). But the long-standing practice in U.S. law of establishing government agencies as ex ante gatekeepers for risk does suggest that the Strong Precautionary Principle cannot be so easily dismissed. It is not as alien to U.S. law and values as the critics would have us believe, and it hardly seems "paralyzing" in the many contexts in which it has been applied.

\section{Countering the Critique of Extremism}

Rather than seriously grapple with examples of Strong Precaution in existing law, many critics instead challenge a straw man-a jumble of extremist positions and hard-to-defend results that allegedly flow from Strong Precaution. Critics frequently contend, for example, that the Strong Precautionary Principle amounts to an intolerable command for proponents of potentially harmful technologies to prove zero risk. ${ }^{126}$ As Ronald Bailey charged, "manufacturers would have to prove that their creations wouldn't cause harm-ever-to the environment or human health before they would be allowed to offer them to the public."127 According to Bailey, this is like "demanding that a newborn baby prove that it will never grow up to be a serial killer, or even just a schoolyard bully ....".128

Zero risk is an undesirable and unattainable goal. ${ }^{129}$ Regulators rarely face a choice between risk and no risk. They must choose instead among various options with different degrees of risk. There is nothing in the Strong Precautionary Principle that precludes priority setting, and I suggest some avenues for doing so in chemical regulation in Part III. To claim that Strong Precaution is a zero-risk standard is merely to set the

126. See, e.g., Giandomenico Majone, What Price Safety? The Precautionary Principle and Its Policy Implications, 40 J. COMMON MARKET STUD. 89, 101 (2002); Christopher D. Stone, Is There a Precautionary Principle?, 31 ENVTL. L. REP. 10790, 10791 (2001).

127. Bailey, supra note 59 , at 39 .

128. Id.

129. See Indus. Union Dep't, AFL-CIO v. Am. Petroleum Inst., 448 U.S. 607, 642 (1980) ('“'[S]afe' is not the equivalent of 'risk-free.' There are many activities that we engage in every day-such as driving a car or even breathing city air-that entail some risk of accident or material health impairment, nevertheless, few people would consider these activities 'unsafe."'). 
straw man on his post. Zero risk is an easy target to knock down, but it misses the crux of the debate.

Sunstein is one detractor who paints the Strong Precautionary Principle as almost comically extreme. After noting the acceptability of weaker versions of the Precautionary Principle, he defines the Strong Precautionary Principle as the view that "regulation is required whenever there is a possible risk to health, safety, or the environment, even if the supporting evidence remains speculative and even if the economic costs of regulation are high." 130

This is the definition of the "Precautionary Principle" that Sunstein excoriates in his 2005 book, Laws of Fear, and in his major article in University of Pennsylvania Law Review, in which he encourages us to move "Beyond the Precautionary Principle."131 But notice that his definition is far more extreme and risk averse than the Wingspread Statement, which is widely considered to be emblematic of the Strong Precautionary Principle. Sunstein's definition, commanding regulation for all "possible" risks, even when based on "speculative" science, is a caricature of advocates' arguments. Sunstein neglects that most formulations of Strong Precaution specifically contemplate approval of activities that may pose serious health or environmental threats, as long as their risks are justified by their proponents as tolerable or within prescribed bounds. Strong Precaution does not require the elimination of all risk nor the elimination of risk at any cost.

What Sunstein has done is to take, as the basis for his definition, some of the most radical formulations of the Precautionary Principle ever committed to paper. ${ }^{132}$ Because Sunstein defines the Strong Precautionary Principle in this way, it is not surprising that he is able to attack it at length. Revealingly, he states that the strongest versions of the Precautionary Principle, embodied in his own definition, might reflect "a po-

130. SUNSTEIN, supra note 12 , at 24 ; see also Sunstein, supra note 15 , at 1018 .

131. SUNSTEIN, supra note 12; Sunstein, supra note 15. In addition, at the end of Laws of Fear, Sunstein described the Precautionary Principle as "a plea for aggressive regulation of risks that are unlikely to come to fruition." SUNSTEIN, supra note 12, at 224.

132. In defining Strong Precaution, Sunstein relies on some rather obscure pronouncements as representative examples of the Principle. In particular, Sunstein's definition of the Principle echoes two obscure and highly risk-averse definitions that he discusses in Laws of Fear. See SUNSTEIN, supra note 12, at 19-20 (quoting Dr. Brent Blackwelder, President, Friends of the Earth, Address Before the Senate Appropriations Committee, Subcommittee on Labor, Health and Human Services (Jan. 24, 2002) ("[T]he Precautionary Principle mandates that when there is a risk of significant health or environmental damage ..., and when there is scientific uncertainty [about the risk], then decisions should be made so as to prevent such activities from being conducted unless and until scientific evidence shows that the damage will not occur.")); Final Declaration of the First European Seas at Risk Conference, Oct. 26-28, 1994, Annex 1, II 4. ("II]f the 'worst case scenario' for a certain activity is serious enough then even a small amount of doubt as to the safety of that activity is sufficient to stop it taking place."). Sunstein describes both formulations of Strong Precaution as being at the "extreme" end of a continuum. SUNSTEIN, supra note 12 , at 18 . Such statements have never had much influence on the practical design of regulatory regimes in the United States. Nonetheless, Sunstein incorporates strikingly similar language into his own definition of the Strong Precautionary Principle, and then proceeds to attack it. See id. at 18-20. 
sition that no one is ultimately willing to hold."133 This raises the question of why he has adopted that definition as his foil, rather than definitions of the Principle more widely accepted in the literature.

Most formulations of the Strong Precautionary Principle, including my own definition and that of the Wingspread Statement, offer far more flexibility than this extreme portrait painted by the critics. ${ }^{134}$ The Strong Precautionary Principle does not impose a burden on any party to prove zero risk, nor does it state that all activities that pose a possible risk must be prohibited. Rather, the Principle, while shifting the burden of proof away from government, deliberately leaves the relevant standard of proof open-ended and subject to democratic deliberation. The Principle requires that a proponent demonstrate that its product or activity meets a specified standard (predetermined through legislation) for how much risk is tolerable or acceptable in a given issue area.

This standard of proof can be set in a variety of ways, just as governing risk standards vary considerably in current public health and environmental statutes, which may prescribe specific safety technologies, set performance benchmarks, impose cost-benefit tests, or set minimal health-based standards. ${ }^{135}$ In some cases, policy makers might choose to adopt a cost-benefit test within a Strong Precautionary framework, requiring the applicant to show that the benefits of its activity outweigh potential harms. The Strong Precautionary Principle is not necessarily antithetical to cost-benefit analysis, though it has often been framed this way in the literature. Under a Strong Precautionary framework, cost-benefit analysis could still be conducted, but it would be the applicant, rather than the government, who would carry both the analytical burden of conducting the analysis and the burden of persuasion. Utilitarian welfare maximization would remain the ultimate goal of the process, but in contrast to the way cost-benefit analysis is traditionally performed, some ex ante precautionary restrictions would be imposed on the activity until the applicant has met its burden to prove that the activity is worth the risks.

There are many options other than cost-benefit balancing that could be used to implement the Strong Precautionary Principle in concrete legislation. In situations where both the probability of harm and the nature of the outcomes are uncertain, cost-benefit balancing is accomplished only through heroic modeling assumptions that obscure the underlying uncertainties and value choices. ${ }^{136}$ Cost-benefit analysis also deals awk-

133. SUNSTEIN, supra note 12 , at 24 .

134. The Wingspread Statement, for example, provides that the burden of proof shall be borne by the proponent of the activity, but it does not itself supply the standard for determining when the burden of proof is met. Id. at 19.

135. See Toxic Substances Control Act $\$ 6(a), 15$ U.S.C. $\$ 2605(a)$ (2006) (stating that the EPA must prove "unreasonable risk" to restrict a chemical); Clean Air Act $\$ 109,42$ U.S.C. $\S 7409$ (b)(1) (2006) (stating that the EPA is required to set ambient air quality standards at a level "requisite to protect the public health" with an "adequate margin of safety").

136. See, e.g., FRANK ACKERMAN \& LiSA HEINZERLING, Priceless: ON KNOWING THE PRICE OF EVERYTHING AND THE VALUE OF NOTHING 10 (2004) ("Cost-benefit analysis of health and environ- 
wardly with equity concerns, including inter-generational equity. It sends a "go" signal to activities that may externalize billions of dollars in health costs on a population, as long as the related benefits in corporate profits and employment are higher than the expected costs. This Article is not meant as a comprehensive critique of cost-benefit analysis, but it does highlight why it is appropriate to establish precautionary risk management regimes that do not rest on such analysis-and not just for a narrow class of "catastrophic" risks. ${ }^{137}$

Utilitarian welfare maximization need not be the driving goal of every regulatory regime, and the Strong Precautionary Principle can incorporate a wider variety of goals and values. For example, a statute might require the applicant to prove that the proposed activity will not cause substantial harm to human health, that it will incorporate bestavailable safety or pollution control technology, or that it will not substantially harm significant ecosystems. ${ }^{138}$ In the hazardous waste context, the Principle would not forbid a firm from engaging in long-term storage of hazardous waste nor would it require complex cost-benefit balancing for each individual storage facility. Rather, the Principle, quite sensibly, would impose a default prohibition on long-term hazardous-waste storage until the firm can demonstrate, ex ante, that the storage will be conducted safely-meaning in accordance with prescribed standards for construction, monitoring, financial security, labeling, and emergency response. The Principle is contextual and pragmatic. It allows policy makers to assess the seriousness of risks and to develop appropriate re-

mental protection rests on simplistic, implausible hypotheses...."); KYSAR, supra note 64, at 71-75 (contrasting situations of "risk," which can be modeled reasonably well because outcomes and probabilities are well defined, with situations of "uncertainty" and "ignorance," typical in environmental policy making, in which probabilities are poorly defined).

137. Sunstein "reconstructs" the Precautionary Principle as an Anti-Catastrophe Principle, and he argues that so reconstructed, his Anti-Catastrophe Principle "deserves to play a role in regulatory choices." SUNSTEIN, supra note 12, at 114. His description in Laws of Fear of how an AntiCatastrophe Principle might operate is quite vague, however. He contends that policy makers should identify and then address worst-case scenario risks, but only when that scenario is in some sense "catastrophic," and even then, only "when the costs of reducing those dangers are not huge and when incurring those costs does not divert resources from more pressing problems." Id. But this leaves a very small scope for precautionary thinking in regulatory law, since addressing catastrophic risks (his primary example is global warming) will almost always necessitate large costs. Moreover, the Strong Precautionary Principle, properly understood, has much wider applications than addressing planetaltering "catastrophic" risks affecting hundreds of millions of people. As the examples in this Article illustrate, the Principle can be applied in a variety of contexts on a more quotidian basis to protect health and safety.

138. That Strong Precaution may introduce values other than strict economic efficiency into the regulatory process is one of the reasons it has drawn such heated criticism. But many existing health, safety, and environmental statutes also impose requirements other than strict cost-benefit tests, such as the use of minimum safety equipment, the adoption of best-available technology, or the avoidance of significant risk. See statutes cited supra notes 114-124. As Sunstein himself has noted, a democratic society may appropriately set regulatory standards with reference to values other than economic efficiency. See SunSTEIN, supra note 12, at 129 ("Efficiency is relevant, but it is hardly the only goal of regulation. Citizens in a democratic society might well choose to protect endangered species, or wildlife, or pristine areas, even if it is not efficient for them to do so."). 
sponses in a much more qualitative way than staunch advocates of a costbenefit test would tolerate.

The governing risk standard-what, exactly, the proponent must show or prove-is not set forth in the Principle itself, but rather in implementing legislation, enacted through democratic processes. Sunstein and other critics are asking far too much from a brief principle when they criticize it for failing to answer complex questions about the valuation of human life ${ }^{139}$ or the distributional consequences of risk decision making. ${ }^{140}$ The Principle was never intended for these purposes; the proper venue for resolution of these questions is implementing legislation. ${ }^{141}$

In addition to providing flexibility to design risk standards, the Strong Precautionary Principle also affords flexibility to design default regulatory responses in the time period before the proponent has met the burden of proof. The extremist critique suggests that the only response of regulators, acting in accordance with the Strong Precautionary Principle, is to ban activities that pose possible or potential risks. ${ }^{142}$ But the Strong Precautionary Principle can be implemented through a variety of defaults beyond simplistic, binary (ban or no-ban) choices. ${ }^{143}$ Appropriate defaults might include partial prohibitions, worker-safety precautions, locational restrictions, or warnings. Even where a regulatory regime provides for a default policy of complete prohibition (as is the case with FDA drug reviews, EPA pesticide registration, and most governmental licensing and permitting programs), the Strong Precautionary

139. See, e.g., Sunstein, supra note 95, at 6 ("Without helping to answer" questions such as the tradeoff between present and future risks and the valuation of a life, "the principle is not useful.").

140. See SUNSTEIN, supra note 12, at 51 ("[T]he Precautionary Principle is a crude, indirect, and sometimes perverse way of incorporating distributional concerns."). But see Applegate, Climate Change, supra note 22, at 176 (arguing that it is "patently not [the] purpose" of the Precautionary Principle to resolve distributional concerns).

141. The necessity of interpretation through implementation does not, however, carve out so much from the Principle itself that the Principle dissolves into vacuity, as discussed in Part I. See also David A. Dana, A Behavioral Economic Defense of the Precautionary Principle, 97 Nw U. L. REV. 1315,1317 ("Principles can express and reinforce value commitments and procedurally structure decisionmaking without dictating a single set of specific, substantive outcomes ...." (emphasis omitted)). Moreover, in existing legislation that incorporates a Strong Precautionary approach, the burden that the proponent or applicant must carry is typically substantial. There is little point in shifting the burden of proof, of course, if the ultimate burden the proponent must carry is a de minimis one. In the ex ante regulatory regimes described supra, the proponent bears a substantial burden to prove that risks or impacts will be within acceptable bounds - a burden that normally takes significant investment of time and resources to meet. The burden-shifting mechanism therefore does real "work" in allocating responsibilities.

142. Kogan, supra note 39, at 494 (The Precautionary Principle "favors banning or severely restricting broad classes of substances, products, and activities if it is merely possible that they ... pose potentially serious but unknown health or environmental harm."); Dave Owen, Probabilities, Planning Failures, and Environmental Law, 84 TUL. L. REV. 265, 270 n.31 (2009) ("A strong precautionary principle might ... ban environmentally threatening activities.").

143. Indeed, it would be a gross waste of resources to implement the same precautionary measures for chemicals whose effects on human health cannot be determined with accuracy as for chemicals that are known carcinogens. "Precautionary measures should be taken in both cases, but with different degrees of stringency." Hansson, supra note 23, at 224. 
Principle clearly provides that the default can be overcome by proof of acceptable risks submitted by the applicant.

\section{Countering the Critique of "Paralysis"}

No one seriously disputes that regulation has opportunity costs, and no serious scholar of risk regulation believes that opportunity costs should be ignored. The FDA's approval process for new drugs, the Federal Aviation Administration's pilot and airport licensing requirements, and the Securities and Exchange Commission's registration requirements for securities all consume public and private sector resources that cannot be deployed elsewhere. Stringent regulation of one activity, moreover, might lead private parties toward substitute activities that pose risks of their own.

The presence of tradeoffs, however, does not mean that the Strong Precautionary Principle is incoherent or paralyzing. Because of the centrality of the "paralysis" theme in the critical literature, I devote substantial attention to that critique here before turning to my proposal for reforms to TSCA.

Several scholars have already examined how policy makers can address tradeoffs in a way that is consistent with the Precautionary Principle. David Dana has suggested, for example, that the Precautionary Principle helps us choose among alternative regulatory actions (including no action) by countering the cognitive tendency to avoid decisions that involve upfront costs and more distant benefits. ${ }^{144}$ Steffen Foss Hansen and Joel Tickner have argued that true risk-risk tradeoffs are less prevalent than the critics have alleged, ${ }^{145}$ and John Applegate has asserted that even where risks inhere on many different sides of a decision, the Precautionary Principle still plays a useful role by ruling out arguments that all decisions should be postponed due to scientific uncertainty. ${ }^{146}$ In a thoughtful examination of risk-risk tradeoffs, Doug Kysar has noted that while the opportunity costs of regulation must be considered, the Precautionary Principle offers a more contextual, dynamic approach for making these tradeoffs than cost-benefit analysis. ${ }^{147}$ The Precautionary Principle, according to Kysar, approaches complex tradeoffs through deliberation,

144. Dana, supra note 141 , at 1333 ("[T]he precautionary principle may have a role to play as a corrective of cognitive biases" in situations where we face "choices between the avoidance of sure, immediate losses and the avoidances of unsure, future losses.").

145. See Steffen Foss Hansen \& Joel A. Tickner, Putting Risk-Risk Tradeoffs in Perspective: A Response to Graham and Wiener, 11 J. RISK RES. 475, 476 (2008) (arguing that many purported riskrisk tradeoffs are hypothetical, never emerged in practice, or were adequately addressed through precautionary regulation).

146. Applegate, Climate Change, supra note 22, at 173, 183-84 (explaining that the function of the Precautionary Principle is primarily procedural and evidentiary).

147. Kysar, supra note 22, at 9 ("Undoubtedly, CBA proponents are correct to note that no society should flatly ignore the opportunity costs of precautionary regulation. But this is a trivial observation, for no serious proponent of the [Precautionary Principle] disagrees with it."). 
moral reflection, and appreciation of the limits of human cognition, while cost-benefit analysis "proceeds awkwardly in the absence of fully characterized risks" and involves questionable monetization of environmental and health harms. ${ }^{148}$

I do not intend to revisit these arguments in detail here. Instead, I offer two responses, underdeveloped in prior literature, to the critique that Strong Precaution is paralyzing for risk decision making-responses that are particularly pertinent to the field of chemical regulation.

\section{a. The Problem of Tradeoffs in Legislation}

My first response is that the detailed, quantitative risk tradeoff analysis that Sunstein, Wiener, Graham, and other critics advocate is often difficult to implement, as a practical matter, within the legislative process. Enactment of legislation is both the primary focus of this Article and the proper focus of analysis of the Strong Precautionary Principle. The Principle should be viewed primarily as a framework to guide legislators, rather than a framework to guide regulators, because, at least in U.S. law, the shift in the burden of proof usually requires some legislative authorization. ${ }^{149}$

In deciding whether to enact a new statute, legislators should of course attempt to identify the tradeoffs involved, including opportunity costs and any countervailing risks. They should also seek to identify ancillary benefits from legislation, other than the intended target effects. ${ }^{150}$ This is simply good decision making.

There is a limited ability, however, in the run-up to passage of new legislation, for legislators or their staffs to perform a comprehensive cost-

148. Id. at 10 .

149. Scholarship on weak versions of the Precautionary Principle has focused overwhelmingly on the decisions of regulatory agencies. See, e.g., Elizabeth Fisher \& Ronnie Harding, The Precautionary Principle and Administrative Constitutionalism: The Development of Frameworks for Applying the Precautionary Principle, in IMPlementing THE PReCautionary PRINCIPLE: PeRsPectives and PRosPects 113, 116 (Elizabeth Fisher et al. eds., 2006) (The Principle applies to "administrative activities" that are "delegated by a primary law maker to a non-elected secondary law maker."). The Strong Precautionary Principle, however, more directly addresses legislative design, given that the key choices, such as the degree of risk that will trigger burden shifting and the showing that must be made to overcome default prohibitions, are usually legislative choices.

150. Interest in risk-risk tradeoff analysis arose in the $1980 \mathrm{~s}$ and $1990 \mathrm{~s}$ in tandem with the rise of cost-benefit analysis in regulatory decision making, and, according to some scholars, risk-risk tradeoff analysis consequently developed a distinct antiregulatory bias. Samuel J. Rascoff \& Richard L. Revesz, The Biases of Risk Tradeoff Analysis: Towards Parity in Environmental and Health-and-Safety Regulation, 69 U. CHIC. L. REV. 1763, 1793 (2002). In particular, Rascoff and Revesz find bias in the identification of the countervailing risks from regulation, without attention to the ancillary benefits of regulation. As an illustrative example of ancillary benefits, they explain that statutes aimed at reducing carbon dioxide emissions, through fuel switching or energy efficiency measures, would also lead to reductions in conventional pollutants such as sulfur dioxide and ozone. Id. at 1808 . They conclude that "[r]isk tradeoffs and ancillary benefits are simply mirror images of each other. There is no justification for privileging the former and ignoring the latter." Id. at 1793. 
benefit analysis on all possible decision-making paths. ${ }^{151}$ Legislators cannot easily predict, for example, how citizens and firms will adjust their behavior in response to various legislative options. Indeed, in enacting a regulatory regime based on delegated authority, legislators cannot be sure of the stringency of the regulations that will be promulgated by an administrative agency, nor can they predict which particular products or activities will be prohibited or allowed, because these decisions will usually be made years later by the agency. Therefore, it is often impossible for legislators to know, in advance, the costs and benefits of different legislative proposals. It is often impossible for legislators to know, in advance, whether Bill $A$ will lead to a Pareto-superior suite of risk reductions compared to Bill $B$ (assuming they are even cognizant of these subtleties). ${ }^{152}$ Moreover, monetizing projected risk reductions and estimating the cost of legislation is notoriously difficult for environmental and public health statutes. ${ }^{153}$

Risk tradeoff analysis depends on being able to accurately characterize risk and monetize the expected value of all projected harms. If, however, there is credible evidence of serious risk from a certain technology or activity, yet probabilities cannot be attached and dollar values cannot be assigned, we are in the realm of vast uncertainty-precisely the realm where Strong Precaution has the most salience. What is called for in these situations is caution, humility, and a framework that protects public health and the environment while further research is conducted.

151. While cost-benefit analysis is mandated for the major rules of federal regulatory agencies through executive order, Exec. Order No. 12,866, 58 Fed. Reg. 51,735 (Oct. 4, 1993), Congress has chosen, wisely, not to bind itself formally to that requirement through its own rules of procedure.

152. Even in the regulatory arena, where formal risk assessment and cost-benefit analysis are strongly institutionalized in U.S. law, it is often difficult to forecast risk-risk tradeoffs or to estimate their magnitude. Consider a risk-risk tradeoff explored by Sunstein in a 2002 article: promulgating strict standards for arsenic (ten parts per billion or less) under the Safe Drinking Water Act might incentivize households, because of the expense of complying with the standard, to switch to private wells that often contain polluted or contaminated water. Cass R. Sunstein, The Arithmetic of Arsenic, 90 GEO. L.J. 2255, 2271, 2294-95 (2002). Sunstein describes this as a classic risk-risk tradeoff and reports that EPA Administrator Christine Todd Whitman "expressed concern" about this possibility in a television interview. Id. at 2294. But he does not explain how that risk-risk tradeoff could be quantified. It is doubtful that regulators could quantify how many users might actually switch to private wells, how polluted private wells are in those communities, and how users' health would be affected by exposure to diverse contaminants in private wells. This is just one example of a broader problem in risk-risk tradeoff analysis: while it may be possible to spot the existence of a countervailing risk from regulation, it can be exceedingly difficult to quantify it. Nonetheless, the presence of potential countervailing risks can be used as a rhetorical scare tactic to stop introduction of needed health and safety regulation.

153. Even in an ideal world where legislators could presciently name all the benefits and costs (including countervailing risks) that might flow from legislation, monetizing the benefit side of the equation (e.g., ecosystems protected, cancers or birth defects avoided, or life years saved) is notoriously problematic. See, e.g., ACKERMAN \& HEINZERLING, supra note 136; KYSAR, supra note 64; Mandel \& Gathii, supra note 22, at 1045-46 (describing hurdles of uncertainty and valuation in conducting cost-benefit analysis); Percival, supra note 22, at 31-32 (noting that the imperative to quantify the costs and benefits of regulation "may distort decision-makers' perceptions of the levels of uncertainty associated with them"). 
In contexts of serious potential risks and significant uncertainty, a mandate for government to conduct comprehensive cost-benefit analysis on all potential decision options may have pernicious results. Policy makers, under pressure from well-financed contributors and interest groups, may simply delay addressing those harms to human health or the environment that scientists have identified as being serious. ${ }^{154}$ The quest for quantifying all tradeoffs - what Donald Hornstein has called "super synopticism"15s - may lead to a different kind of "paralysis" than the one that Sunstein says is inherent in Strong Precaution: paralysis by analysis. ${ }^{156}$

This concern - that protective health and environmental legislation will be undermined by demands for comprehensive risk tradeoff analysis - is not just hypothetical. The primary reason that the EPA has become crippled in its ability to restrict chemicals already on the market is that TSCA commands the EPA to perform extensive cost-benefit balancing on any decision to restrict a chemical, including identifying the "least burdensome" alternative that will address the risk. ${ }^{157}$ The courts have interpreted this requirement to mean that the agency must conduct costbenefit analysis not only on a proposed restriction of a chemical, but also on a tiered ladder of other possible regulatory alternatives with varying stringency. ${ }^{158}$ The massive information needs of such a task have meant, in practice, that the EPA has not been able to pull known hazardous sub-

154. Use of phthalates in children's toys provides another example of how the presence of tradeoffs need not be paralyzing to decision making. Phthalates, used to soften plastics, are known to be endocrine-disrupting chemicals that can disrupt normal development of sex organs. See Ernie Hood, Are EDC's Blurring Issues of Gender?, 113 ENVTL. HEALTH PERSP. A670, A671 (2005). For this reason, in 2008 , Congress banned several classes of phthalates in children's toys, baby bottles, pacifiers, and other items. See Consumer Product Safety Improvement Act, $\$ 8,15$ U.S.C. $\$ 2057$ (2006). It is conceivable, though speculative, that banning phthalates in children's toys could result in toy manufacturers substituting a more hazardous chemical instead. It is also foreseeable that the ban could lead to some job loss in the affected baby care industries or in the chemical industry. But Congress was not and should not be "paralyzed" by these possibilities of a risk "on the other side." There is nothing in the Precautionary Principle (weak or strong versions) that mandates that the scientifically documented risks of children's exposures to phthalates must be given the same weight in decision making as more speculative countervailing risks. The potential of a countervailing risk should not be used to forestall regulation of risks that we do know about. Moreover, the best solution here is not to accept our ignorance of the alternatives, but rather to require a minimum toxicity data set on a wide universe of chemicals so that the risks of phthalates and any potential alternative chemical in children's toys can actually be compared to each other.

155. Donald T. Hornstein, Lessons from Federal Pesticide Regulation on the Paradigms and Politics of Environmental Law Reform, 10 YALE J. ON REG. 369, 386-87 (1993); see also Bradley C. Karkkainen, Framing Rules: Breaking the Information Bottleneck, 17 N.Y.U. ENVTL. L.J. 75, 81-82 (2008) (criticizing "comprehensive bureaucratic rationality" as an approach to risk).

156. See, e.g., Hansen \& Tickner, supra note 145, at 477 (" $[\mathrm{I}] \mathrm{t}$ is useful to consider realistic and reasonable risk-risk tradeoffs but ... this should not keep us from acting on a risk for which there is scientific evidence indicating concerns."); see also Percival, supra note 22, at 79 (rejecting the proposition that "a never-ending quest for improved information should indefinitely postpone sensible regulatory measures"); Rascoff \& Revesz, supra note 150.

157. TSCA $\$ 6(a), 15$ U.S.C. $\$ 2605$ (a) (2006).

158. See Corrosion Proof Fittings v. E.P.A., 947 F.2d 1201, 1215 (5th Cir. 1991). 
stances off the market, including asbestos, ${ }^{159}$ which is classified as a known carcinogen by both the National Toxicology Program and the International Agency for Research on Cancer. ${ }^{160}$ The U.S. environmental statute most committed to cost-benefit balancing for toxic risks is the one that has been the least effective in addressing them.

Despite the lethargic and unprotective track record of TSCA, Sunstein continues to advocate careful cost-benefit balancing in chemical regulation to determine whether a particular hazardous substance should be restricted from the marketplace. According to Sunstein, government regulators should compare a chemical's risk to human well-being with the benefits we gain from the chemical. ${ }^{161}$ But as Congress takes up TSCA reform, it must recognize that continuing to rely on chemical-bychemical cost-benefit balancing, with a governmental burden of proof is tantamount to unprecautionary regulation.

Moreover, the argument that restrictions on a particular chemical may have both costs and benefits does nothing to undermine the utility of the Strong Precautionary Principle as the guiding rubric for the overall field of chemical regulation. Legislatures confront policy choices at a much higher level of generality than Sunstein's concern about whether to allow or restrict a particular substance. In federal toxics policy, the legislative task is not to perform a utilitarian calculus on the costs and benefits of banning or restricting specific chemicals. It is to determine the best legislative architecture for assessing and managing the risks of the universe of 84,000 chemicals that have been introduced into commerce.

The questions that Congress confronts at the legislative stage are much broader than the substance-specific inquiry that Sunstein advocates, and here, Congress need not be paralyzed in pursuing a goal of caution in the face of risk, even with the knowledge that caution will have its costs. Congress must determine what decision-making procedures and default rules should be put in place for all chemical substances subject to the statute. What kinds of rules would be protective of human health and the environment, given what we know about chemical exposures and toxicity? What kinds of authorities should be given to regulators to compel testing? Who should bear the burden of proof? What must chemical manufacturers show about the risks of a chemical prior to marketing? Should there be trade secret exemptions from public disclo-

159. See discussion of Corrosion Proof Fittings, infra Part II.

160. See Known and Probable Human Carcinogens, AM. CANCER SOC'Y, http://www.cancer.org/ Cancer/CancerCauses/OtherCarcinogens/GeneralInformationaboutCarcinogens/known-andprobable-human-carcinogens (last updated Feb. 17, 2011).

161. See Cass R. Sunstein \& Adrian Vermeule, Is Capital Punishment Morally Required? Acts, Omissions, and Life-Life Tradeoffs, 58 STAN. L. REV. 703, 708 (2005) ("[T]here is general agreement that whether a particular substance ought to be regulated depends on the overall effect of regulation on human well-being."). Note that Sunstein and Vermeule restrict this calculus to "human wellbeing," leaving impacts on nonhuman species out of the equation. Id. 
sure of toxicity data? What kinds of toxicity tests will be acceptable for risk assessment?

These are fundamental value choices, not easily subjected to monetization or cost-benefit analysis. Legislators must, in the end, make a difficult judgment about the best approach to a particular class of risks, one that "represents the self-expressed commitments of an integrated political community." 162 Legislators should consider knowable tradeoffs where they can be quantified, but they should also view their role as more than utility maximizers, summing up individual preferences. The need to accept agency and responsibility in decision making is particularly acute in the enactment of environmental legislation, which raises fundamental questions about duties to current and future generations and stewardship of ecosystems. ${ }^{163}$

A crucial threshold judgment that a legislative body must make in the design of a public health or environmental statute is whether to implement a Strong Precautionary approach - in which a government agency is placed in a risk gatekeeping role with the burden of proof on the applicant. Or, on the other hand, a legislature might decide that a particular arena of risk should be addressed through more laissez-faire mechanisms, by some minimal post-market supervisory authority of a government agency, or perhaps by no regulation at all.

Recall Sunstein's contention that because regulation may cause risks of its own, or deprive society of some significant benefits, "stringent regulation would actually run afoul of the Precautionary Principle."164 Some examples from outside environmental law help to illustrate why legislators need not be paralyzed in choosing to implement a Strong Precautionary framework.

Consider first the licensing of doctors and nurses. There is clearly a risk-risk tradeoff in a decision on whether to enact a licensing statute, with human lives at stake "on all sides" of the choice, to use a favorite phrase of the critics. ${ }^{165}$ Not requiring a license could result in untrained people performing surgeries and prescribing medications. Yet, requiring a license clearly limits the supply of doctors and nurses, which could put lives at risk in medically underserved communities. ${ }^{166}$

162. KYSAR, supra note 64 , at 239.

163. In environmental law, Congress has frequently acted to protect natural resources and human health without engaging in comprehensive risk-risk analysis or cost-benefit balancing. Doug Kysar has noted, for example, that the Clean Water Act's command not to degrade the nation's pristine waters is a fairly absolute one that does not consider tradeoffs regarding how this protection might limit economic development. Id. at 248. The Endangered Species Act can also be seen as a deontological, nonutilitarian statute reflecting a national value that species should be protected. $I d$.

164. SUNSTEIN, supra note 12, at 29.

165. Sunstein, supra note 15 , at 1054.

166. Strict medical licensing requirements could easily lead to adverse health outcomes for patients. The Department of Health and Human Services has reported that sixty-five million Americans live in "Health Profession Shortage Areas," and that it would take an additional 16,643 primary care physicians in these areas to serve the populations adequately. See Shortage Designation: HPSAs, 
But why should applying the Strong Precautionary Principle be "paralyzing" here? Would we really say that either decision would be equally precautionary, or that a precautionary legislator would find it impossible to decide? Consistent with the Strong Precautionary Principle, legislators have made a judgment (in all fifty states) that it is better to have a default rule prohibiting unlicensed medical practice, with the applicant bearing the burden of proof on their qualifications for the license, ${ }^{167}$ rather than to allow any person to practice medicine and then respond to any resulting harm on an ex post basis. We do not consider costs and benefits in deciding whether a particular nurse or doctor should be allowed to enter the market for medical services (the kind of individualized determination that Sunstein has advocated for chemical substances). We instead implement a firm rule that applies to all practitioners in every state: if you want to practice medicine, you must bear the burden to prove, ex ante, that you have the required skills, training, and knowledge. That there are some inevitable tradeoffs in grounding medical licensing rules in the Strong Precautionary Principle does not eviscerate the coherence of Strong Precaution as an approach to risk.

As another example of why a Strong Precautionary approach need not be "paralyzing" in the presence of tradeoffs, consider federal and state laws on operation of new airports, which require applicants to receive ex ante government approval for construction and operation. ${ }^{168}$ The goals of such statutes are to avoid overcrowding in the skies resulting from locating airports too close to each other and to guarantee some minimal safety standards for airport facilities. ${ }^{169}$ Under federal law, the FAA does not determine whether the benefits of a proposed airport (measured in terms of economic growth, tax revenue, or recreational enjoyment) exceed the potential risks. ${ }^{170}$ Rather, airport preapproval statutes are prescriptive. They say to the operator: given potential serious threats to public safety from a poorly located or poorly operated airport,

MUAs \& MUPs, HEALTH RES. \& SERVICES ADMIN., http://bhpr.hrsa.gov/shortage/ (last updated May $28,2010)$.

167. See, for example, the medical licensing statutes of New York and Texas, which are virtually identical to the other states. N.Y. EDUC. LAW $\S 6501$ (McKinney 2010) (requiring a license to practice medicine); Id. $\S 6512$ (stating that it is a felony to practice medicine without a license); TEX. OCC. CODE ANN. $\$ 155.001$ (West 2007) (describing procedures for issuance of medical licenses); Id. $\S 165.152$ (stating that it is a felony to practice medicine without a license).

168. See Notice of Construction, Alteration, Activation, and Deactivation of Airports, 14 C.F.R. $\S 157$ (2010); U.S. DEP'T OF TRANS. \& FAA, NotICE OF LANDING AREA Proposal, FAA Form 74801, http:/www.faa.gov/documentLibrary/media/form/faa7480-1.pdf; MINN. STAT. $\$ 360.018$ (2010) ("The general public interest and safety, the safety of ... persons and property on the ground, and the interest of aeronautical progress [require] ... that airports, restricted landing areas, and air navigation facilities should be suitable for the purposes for which they are designed ...."); MINN. R. 8800.1400 (2007) (establishing notification and licensing requirements for new airports).

169. See Part 157 Notice of Construction, Alteration, Activation, and Deactivation, FED. AviATION ADMIN., http://www.faa.gov/airports/central/engineering/part157/ (last updated Apr. 12, 2010) ("Notification allows the FAA to identify potential aeronautical hazards in advance thus preventing or minimizing the adverse impacts to the safe and efficient use of navigable airspace.").

170. See id. 
government will hold you to specific safety standards and forbid you from engaging in airport operation until you can prove that your facility meets the standards, even if there are significant foregone economic benefits from prohibiting airport operation. ${ }^{171}$ The Strong Precautionary Principle's salutary signals are very much present here-legislators demand compliance with minimum safety standards, place the burden of proof on the applicant to show that risks will be acceptable, and allow vigorous competition to occur within that framework.

\section{b. Addressing Tradeoffs Within Precautionary Legislation}

My second response to the criticism that Strong Precaution necessarily ignores risk-risk tradeoffs is that such tradeoffs can often be addressed within regulatory regimes grounded in Strong Precaution. Indeed, the shift in the burden of proof to proponents may highlight policy alternatives that may not come to light under traditional decision-making frameworks.

There are numerous examples of permitting, licensing, and preapproval statutes that implement a default prohibition on a certain targeted activity, yet also contain procedures to address known countervailing risks of the prohibition. In drug approvals, for example, the FDA has developed three separate programs (fast track, accelerated approval, and priority review) to reduce "drug-lag," shortening the time in which breakthrough drugs can move to market. ${ }^{172}$ Pharmaceutical manufacturers under those programs still cannot market a new drug until they receive FDA approval, but they proceed down a separate and faster track within the agency. ${ }^{173}$ Environmental statutes that rely on licensing and preapproval mechanisms are replete with "minor source," "minor use," and "experimental use" exemptions, to avoid applying strict research, preapproval, and pollution control requirements to activities that, as a class, pose less severe risks. ${ }^{174}$

In arguing that the presence of risk-risk tradeoffs makes precaution incoherent, Sunstein, Graham, Wiener, Cross, and other critics often

171. See id.

172. Fast Track, Accelerated Approval and Priority Review: Accelerating the Availability of New Drugs for Patients with Serious Diseases, U.S. FOOD \& DRUG ADMIN., http:/www.fda.gov/For Consumers/ByAudience/ForPatientAdvocates/SpeedingAccesstoImportantNewTherapies/ucm1282 91.htm (last updated May 28, 2010).

173. Id.

174. See, e.g., FIFRA, 7 U.S.C. $\$ 136$ p (2006) (granting emergency use exemptions from the registration and preapproval process for pesticides); $i d$. $\$ 136 \mathrm{c}$ (2006) (outlining experimental use exemptions); Clean Air Act, 42 U.S.C. $\$ 7475$ (2006) (applying preconstruction review requirements of the Prevention of Significant Deterioration program only to "major emitting facilities," defined by pollutant tonnage thresholds); Resource Conservation and Recovery Act of 1976, 42 U.S.C. $\$ \S 6921,6924$ (2006) (outlining less-stringent storage and labeling requirements for "small quantity generators" and "conditionally exempt small quantity generators"). 
point to the same example: DDT. ${ }^{175}$ The critics explain that banning DDT could lead to increased deaths from malaria in the developing world. ${ }^{176}$ Given this countervailing risk of a DDT ban, critics suggest, a goal of caution is paralyzing. ${ }^{177}$ Is it cautious to ban DDT or to do the opposite? When international negotiators actually confronted this tradeoff in the design of the Stockholm Convention on Persistent Organic Pollutants, they formalized a global ban on the production and use of DDT and then provided an exception for parties that register their intent to continue to use DDT for mosquito control. ${ }^{178}$ Through permitting optouts from the global ban, negotiators achieved a compromise that addresses both the target risk (environmental and health harms from DDT) and one countervailing risk of a ban (malaria).

Strong Precaution does not inexorably lead to abdication of judgment. It does not doom legislators to extremist positions in which known, countervailing risks and the costs of legislation must be ignored. Rather, as the above examples illustrate, legislators can structure a Strong Precautionary regulatory regime to address both the "target risk" and countervailing risks.

For a particularly elegant example of this in chemical regulation, consider REACH, the EU chemical legislation discussed previously. ${ }^{179}$ The EU explicitly grounded the legislation in the Precautionary Principle, ${ }^{180}$ and the legislation relies heavily on burden shifting. In particular, REACH imposes a default sunset date after which a chemical identified as a "very high concern" substance cannot be marketed in the EU. ${ }^{181}$ "Very high concern" is a term of art, defined in REACH in reference to the intrinsic properties and hazards of the chemical (such as carcinogenicity or bioaccumulative properties). ${ }^{182} \mathrm{REACH}$ further provides that chemical manufacturers can overcome the default and receive authorization to market a "very high concern" chemical through demonstrating, among other things, that the socioeconomic benefits of the chemical exceed potential costs. ${ }^{183}$

175. See indur M. Goklany, The Precautionary Principle: a Critical appraisal of ENVIRONMENTAL RISK ASSESSMENT 26-27 (2001); SUNSTEIN, supra note 12, at 32; Cross, supra note 88, at 890-91; Sunstein \& Vermeule, supra note 161, at 707; see also RICHARD TREN \& ROGER BATE, COMPETITIVE ENTER. INST., WhEN POLITICS KILlS: MALARIA AND THE DDT STORY 25-26 (2000), http://cei.org/PDFs/malaria.pdf.

176. See GoKLANY, supra note 175 , at 27 ; SUNSTEIN, supra note 12 , at $32-33$; Cross, supra note 88 , at $890-91$.

177. SUNSTEIN, supra note 12, at 32-33; see also GoKLANY, supra note 175, at 27.

178. Stockholm Convention on Persistent Organic Pollutants, Annex B.II, May 22-23, 2001, opened for signature May 23, 2001, 40 I.L.M. 532 (2001). Under Annex B.II of the Convention, continued use of DDT is subject to developing an implementation plan that includes a search for suitable alternatives to DDT. Id.

179. See supra notes $75-79$ and accompanying text.

180. See REACH, supra note 75 , at 396 .

181. See Sachs, supra note 2 , at $1837-38$ (providing an overview of REACH).

182. Id. at 1837.

183. Id. at 1838 . 
$\mathrm{REACH}$ provides an important reminder that a Strong Precautionary regulatory regime need not preclude consideration of the costs and benefits of regulation. In a twist on prevailing approaches in the United States, however, REACH shifts the burden of conducting the costbenefit analysis to the manufacturer that seeks to continue to market a chemical substance with known hazardous properties. ${ }^{184} \mathrm{REACH}$ also requires that manufacturers, in the authorization process, analyze whether less hazardous substitute chemicals exist. ${ }^{185}$ In this way, the "stop and think" mechanism of Strong Precaution, far from ignoring tradeoffs, becomes the spur for a formal alternatives analysis that has never been a prominent part of U.S. chemical regulation.

\section{The Limits of Strong Precaution}

The Strong Precautionary Principle provides a framework to protect public health and safety, and some advocates of the Principle naturally want to universalize it as a guiding polestar for all areas of risk. As the authors of the Wingspread Statement put it, "[c]orporations, government entities, organizations, communities, scientists, and other individuals must adopt a precautionary approach to all human endeavors." 186

The Principle has some significant limitations, however, and it needs to be applied judiciously. For one thing, many forms of human health and environmental risks have no "proponent" to which the burden of proof can be shifted. Consider natural disasters, the spread of contagious disease, or the remediation of historic contamination at a hazardous waste site. We need government to take appropriate preparations for these risks, and in the case of historic waste sites, to set appropriate cleanup standards, but there is no private "proponent of the activity" who can bear the burden of proof. Climate change is another example of a problem not easily addressed through burden-shifting mechanisms. A climate change strategy must include promoting energy efficiency and pricing greenhouse gas emissions, ${ }^{187}$ and arguments over burden of proof would merely distract from those urgent national tasks. ${ }^{188}$

184. Id.; see also Wagner, supra note 87 , at 473 (noting that a system in which cost-benefit analysis is used by manufacturers to rebut precautionary health-based regulation would be consistent with the Precautionary Principle).

185. See Sachs, supra note 2, at 1841-42 (discussing REACH's incentives for development of substitutes for hazardous chemicals).

186. See, e.g., Protecting Public Health \& THE Environment, supra note 23 app. A, at 353 (emphasis added). The context of this quotation makes it clear that the authors were describing the Strong Precautionary Principle, as the Wingspread Statement goes on to provide a definition of precaution that includes burden shifting. See id. at 353-54.

187. See Noah M. Sachs, Greening Demand: Energy Consumption and U.S. Climate Policy, DuKE ENVTL L. \& POL'Y F. 295, 298 (2009).

188. I do not mean to minimize the role of precautionary steps in addressing climate change. Policy making should still be guided by weaker versions of the Precautionary Principle, allowing early action in the face of scientific uncertainty. For more on the role of precaution in the climate debate, see Applegate, Climate Change, supra note 22. 
A second reason that Strong Precaution should not be viewed as universally applicable is that putting government in a risk gatekeeping role can be complex, potentially anticompetitive, and expensive. $\mathrm{PhD}$ level government personnel would often be needed to review risk data compiled by private parties and to determine (subject to layers of judicial review) whether the proponent has met its burden of proof. The expansion of agency bureaucracy that would result from indiscriminate application of Strong Precaution would be a counterintuitive outcome from a principle designed to shift the burden of proof away from government.

For these reasons, the gatekeeping mechanism of the Strong Precautionary Principle should be reserved for serious threats that cannot be addressed through less intrusive mechanisms. For many forms of risk, there is no need to resort to the aggressive ex ante approach to risk implicit in the Strong Precautionary Principle. Consider, for example, performing surgery, marketing a dangerous recreational activity (e.g., sky diving), or marketing a dangerous power tool (e.g., chainsaw, jackhammer). These all raise serious safety risks, but the liability system, insurance, and tort-based deterrence have performed reasonably well for addressing these risks in the United States. There is no need to institute complex legal mechanisms for risks that are already being handled acceptably through less aggressive means.

The most pressing issue for legislators, therefore, is how to make the fundamental judgment alluded to in the prior section: determining when it makes sense, despite attendant complexity, to implement the Strong Precautionary Principle as the basis for a risk regulatory regime. Relevant criteria should include the administrative costs of establishing an ex ante review mechanism; the suitability of tort remedies or criminal penalties to address the risk; whether risk creators are likely to be judgment proof in the event that harm occurs; whether the risk is one to which participants consent (as in surgery or in dangerous recreational activities), or is in the nature of a nonconsensual externality; and whether the risk could be addressed adequately through postmarket regulatory mechanisms. ${ }^{189}$

In this Article, I do not intend to explore these criteria in detail, but I have provided numerous examples of successful operation of the Principle in different regulatory contexts. ${ }^{190}$ As I argue below, Congress should implement the Principle in chemical regulation-a field defined by serious potential risks, uncertainty regarding health hazards and exposure pathways, and deficient postmarket mechanisms for addressing the risks.

189. Steve Shavell explored some of these same criteria nearly thirty years ago in his classic article on the merits of liability rules versus public regulation as tools for risk management. See Shavell, supra note 62.

190. See discussion supra Part II.B.1. 


\section{ImPlementing StRong PRECAUTION IN ChemicAl Regulation}

The current system of U.S. chemical regulation is deeply flawed. It leaves Americans exposed to thousands of untested synthetic chemicals that could cause cancer, problems in gene expression, birth defects, and infertility. Although Congress intended the statute as an early warning system for chemical risks, TSCA has failed to generate basic toxicity data for the vast majority of chemicals now in commerce. ${ }^{191}$ As a result, chemicals used in consumer products, food packaging, clothing, toys, plastics, and other products remain untested for their health effects. Moreover, only a fraction of all air pollutants have ever been tested for toxic characteristics. ${ }^{192}$ U.S. children consequently enter the world "prepolluted," having been dosed in utero with dozens of industrial chemicals (through the mother's lifetime exposure) that have never been tested for their health effects. ${ }^{193}$

In this Part, I discuss how the Strong Precautionary Principle could contribute to a more effective chemical regulatory system in the United States. I provide a brief summary of what has gone wrong in U.S. chemical regulation, supplementing a prior article where I discussed the flaws of TSCA at some length. ${ }^{194}$ I then outline how the Strong Precautionary Principle should be implemented in the next generation of U.S. chemical regulation to remedy these problems. My goal here is to concretize the debate over the Strong Precautionary Principle, which often dissolves into airy abstraction, through showing how the Principle could advance reform of an existing statute.

\section{A. The Hollow Hope of TSCA}

TSCA has never lived up to the ambitious expectations of its drafters, ${ }^{195}$ who envisioned TSCA as a highly preventive "capstone" statute of U.S. environmental law. ${ }^{196}$

191. EPA's Integrated Risk Information System, the agency's compendium of data on the health effects of chemicals, has full risk assessments for only 540 substances, and EPA reported in 2003 that 287 of these assessments may be out of date. U.S. GOV'T ACCOUNTABILITY OFFICE, GAO-08-743T, TOXIC CHEMICALS: EPA's NEW ASSESSMENT PROCESS WILl INCREASE CHALLENGES EPA FACES IN EVAluating and Regulating ChEmicals 6 (2008). EPA has ordered testing under Section 4 of TSCA for approximately 200 of 84,000 chemicals in the TSCA inventory. GAO, ENHANCING TSCA, supra note 2 , at 5 .

192. Less than two hundred substances out of thousands of chemicals emitted to the ambient air are regulated as hazardous air pollutants under the Clean Air Act. See 42 U.S.C. \$ 7412(b) (2006). Moreover, the firms emitting these pollutants are not required to eliminate emissions, but only to install maximum achievable control technology. Id. \$ 7412(d)(2)

193. Kid-Safe Chemicals, ENVTL. WORKING GRP., http://www.ewg.org/kid-safe-chemicals-actblog/kid-safe-chemicals-act (last visited June 2, 2011). See also ENVTL. WORKING GRP., POLLUTION IN PEOPLE: CORD BloOD CONTAMINANTS IN MINORITY NEwBORNS (2009), http://www.ewg.org/files/ 2009-Minority-Cord-Blood-Report.pdf; Woodruff et al., supra note 4.

194. Sachs, supra note 2, at 1825-33.

195. Some of the main players in the congressional debate viewed TSCA as a highly anticipatory statute in which chemical manufacturers would bear the principal burdens of research, testing, and 
One fundamental problem with the statute is its sharply divergent regulatory treatment of "new" chemicals and those that were already on the market before 1979 (so-called "existing" chemicals). About seven hundred new chemicals are manufactured each year, ${ }^{197}$ and for these new chemicals, manufacturers must submit a Premanufacture Notice (PMN) to the EPA listing the structure and properties of the substance. ${ }^{198}$ EPA has a ninety-day window to take any regulatory action, ${ }^{199}$ but significantly, TSCA does not require that manufacturers submit toxicity data or conduct any safety testing on new chemicals as part of the PMN process. ${ }^{200}$

Consequently, while TSCA's new chemicals notice program bears a superficial resemblance to an ex ante review process, it cannot be said to reflect the Strong Precautionary Principle. Some scholars have referred to TSCA's PMN procedure as an example of burden shifting in U.S. environmental law, ${ }^{201}$ but as John Applegate has explained, "[t]he PMN requirement is less a licensing requirement than a sieve." ${ }^{202}$ Unlike U.S. law governing pharmaceuticals and pesticides, TSCA imposes no affirmative burden on the manufacturer to research the toxicity of new chemicals, and manufacturers have no obligation to prove that a new chemical poses acceptable, nonsignificant risks to human health.

Due to resource constraints and statutory hurdles to testing, the farlarger class of more than 60,000 "existing" chemicals, introduced before 1979 , has received little regulatory scrutiny. ${ }^{203}$ Congress grandfathered

disclosure. See Legislative History of the Toxic Substances Control Act, 94th Congress at 215 (statement of Senator James Pearson) ("We can no longer operate under the assumption that what we do not know about a chemical substance cannot hurt us. Tragic results associated with too many toxic substances have taught us that lesson all too well. Chemicals, not people, must be put to the test.").

196. See James T. O'Reilly, Torture By TSCA: Retrospectives of a Failed Statute, NATURAL RESOURCES \& ENV'T, Summer 2010, at 43, 43. O'Reilly, currently a professor at the University of Cincinnati College of Law, was a lobbyist for Procter \& Gamble in the 1970s and participated in many of the crucial negotiations that led to the passage of TSCA. Looking back on the legislative debate over TSCA, he recently concluded that, "[t]his was a lobbying effort so effective, in retrospect, that TSCA has been far less successful than its sponsors had hoped. My 'side' won in 1976. TSCA has failed and left us with a mere façade of effective environmental action." Id.

197. See U.S. Gov't ACCOUNTABILITY OfFICE, GAO-10-292T, ChEMICAL Regulation: OBSERVATIONS ON IMPROVING THE TOXIC SUBSTANCES CONTROL ACT 2 (2009).

198. Toxic Substances Control Act $\S 5$ (a), 15 U.S.C. $\S 2604$ (a) (2010).

199. Id. See also Adelman, supra note 80, at 389 (calling the PMN review process "perfunctory" and noting that the ninety-day window for EPA review is often "preclusive of regulatory action"). The EPA relies principally on computer modeling in its new chemical review process, and given resource constraints, only twenty percent of PMNs submitted receive a detailed review. GAO, OPTIONS ExIST, supra note 2, at 11-12.

200. Manufacturers must disclose toxicity information about a new chemical only if such information is in the manufacturer's "possession or control" or if it is "known to or reasonably ascertainable by" the submitter. Premanufacture Notification, 40 CFR $\$ \$ 720.50(a)-(b)(2010)$. Under this "disclose it if you have it" model, it is not surprising that only fifteen percent of PMNs contain any health and safety information. GAO, OPTIONS EXIST, supra note 2, at 11.

201. See, e.g., Bodansky, supra note 34, at 209-10; Wiener, supra note 35, at 1523.

202. Applegate, supra note 33 , at 432.

203. Existing chemicals represent about seventy-eight percent of all chemicals that have been introduced into commerce in the United States. Sachs, supra note 2, at 1826-27. But by volume, pre- 
these existing chemicals, and they are not subject to risk assessment requirements except on an ad hoc basis through postmarket testing requirements under Section 4 of TSCA. ${ }^{204}$ EPA has exercised this postmarket testing authority for only two hundred chemicals. ${ }^{205}$ The grandfathering of existing chemicals has no basis in toxicology, of course, and the legislative choice to exempt existing chemicals from routine testing now means that comprehensive toxicity data is available for just a fraction of all chemicals used in the United States. ${ }^{206}$ The main problem that TSCA was meant to address-lack of data on chemicals-has not been solved, thirty-five years after TSCA's enactment. ${ }^{207}$

Where scientific evidence does suggest that a chemical poses serious risks to human health or the environment, TSCA raises significant barriers for EPA to restrict the chemical - the opposite of precautionary risk management. ${ }^{208}$ I discussed the complex statutory procedures under which EPA must prove "unreasonable risk" previously, in the context of the Fifth Circuit's rejection of EPA's ban on asbestos. This governmental burden of proof in chemical regulation has meant, in practice, that the government has barely regulated at all, at least with respect to existing chemicals already on the market. Moreover, while the Strong Precautionary Principle calls for proportional regulatory responses, TSCA creates a one-size-fits-all system in which EPA must meet the same statutory burden of proving "unreasonable risk" whether it wants to enact a complete ban, simply restrict certain uses, or impose labeling requirements on a chemical. ${ }^{209}$

TSCA is fundamentally unprotective - the "lapdog of American environmental law."210 In 2009, the Government Accountability Office named EPA's toxics regulatory program a "high risk" government program, needing "broad-based transformation" and priority attention from

1976 existing chemicals still account for ninety-nine percent of the chemicals in commerce. Adelman, supra note 80 , at $389-90$. So if the new chemicals program is viewed as a precautionary "pocket" in the statute, as Wendy Wagner has suggested, it is a narrow pocket indeed. Wagner, supra note 87, at 285-86. While TSCA authorizes testing of existing chemicals, "it generally provides no specific requirement, time frame, or methodology for doing so.... As a result, EPA does not routinely assess the risks of the more than 83,000 commercial chemicals in use." GAO, supra note 197 , at 4 .

204. Toxic Substances Control Act, 15 U.S.C. $\$ 2603$ (2006).

205. GAO, supra note 198 , at 5.

206. See supra note 204 and accompanying text.

207. These statutory flaws have been exacerbated by insufficient funding for TSCA. Historically, the number of agency personnel devoted to TSCA implementation has been less than the number devoted to implementation of FIFRA, the statute governing pesticides, despite the fact that pesticides represent a far smaller universe of chemicals. See Mark A. Greenwood, TSCA Reform: Building a Program That Can Work, 39 ENVTL. L. REP. 10034 (2009).

208. For example, EPA can enact restrictions on a chemical only after a full trial-type hearing; it must make a series of statutory findings prior to restrictions. it must choose the "least burdensome" regulatory requirement that will adequately protect against the risk, and it must demonstrate that no other statute could address the concern. 15 U.S.C. $\$ 2605$ (a), (c).

209. See Denison, supra note 4, at 10022 (discussing TSCA's uniform "unreasonable risk" standard and comparing it to the goal of proportionality of regulatory response in the Precautionary Principle).

210. Sachs, supra note 2, at 1818. 
the Obama administration and Congress. ${ }^{211}$ EPA Administrator Lisa Jackson testified in 2009 that TSCA is "outdated and does not provide the tools to adequately protect human health and the environment as the American people expect, demand and deserve."212

At the same time that the weaknesses of TSCA have become apparent, it has also become clear that the tort system does not provide an adequate backstop or substitute for regulatory oversight. In a recent book comparing European and U.S. risk regulation, Donald Elliott and Ortwinn Renn suggest that despite clear flaws in TSCA, the overall system of chemical regulation in the United States remains protective of human health and is roughly as precautionary as Europe's."13 "The potent civil liability system in the United States," they allege, "is at least as important a regulatory system for chemicals as is EPA regulation under TSCA."114 This conclusion, however, runs contrary to decades of scholarship highlighting the inadequacies of the tort system for addressing chemical exposures, given long latency periods and difficulties of proving causation and identifying the proper defendant. ${ }^{215}$ The threat of future liability does not provide an incentive for chemical manufacturers to conduct toxicity research. More likely, the tort system provides incentives for manufacturers not to conduct toxicity research, given that such research would be subject to discovery and that the plaintiff will bear the burden of proof in any civil suit. ${ }^{216}$

Given the weaknesses of existing regulatory and tort remedies for harms from toxic chemicals, Congress should overhaul TSCA through establishing a substantial ex ante licensing and review system for chemical risks. There is a fundamental difference between chemical risks and other kinds of risks, such as those from recreational activities, power tools, and other activities described above, which can be handled reasonably well through informed consent, mutual bargaining, or tort-based deterrence regimes. ${ }^{217}$ In the case of chemical exposures, a person harmed is usually unaware of the exposure, the level of risk posed by the exposure, or the entity that produced the harmful product. Concepts of informed consent, assumption of risk, or Coasian bargaining are inapplica-

211. U.S. GOV'T ACCOUNTABILITY OFFICE, GAO-09-271, HIGH-RISK SERIES: AN UPDATE 22-24 (2009) ("Without greater attention to EPA's efforts to assess toxic chemicals, the nation lacks assurance that human health and the environment are adequately protected.").

212. Lisa P. Jackson, Adm'r, Envtl. Prot. Agency, Testimony before the U.S. Senate Committee on Environment and Public Works (Dec. 2, 2009).

213. Ortwinn Renn \& E. Donald Elliott, Chemicals, in Reality of Precaution: CoMParing RISK REGULATION IN THE UNITED STATES AND EUROPE (Jonathan B. Wiener et al. eds., 2011).

214. Id. at 229.

215. See supra note 62. See also John T. Nockleby, Faces of the Tort Pyramid: Compensation, Regulation, and the Profession, in AN UNFINISHED PROJECT: LAW AND THE POSSIBILITY OF JUSTICE (Scott Cummings ed., 2010) (arguing that the regulatory function of tort law is severely compromised by the vagaries of litigation, such as the desire of plaintiff's lawyers to seek out only those "ideal" plaintiffs with easy-to-prove injuries, high damages, and claims against financially solvent defendants).

216. See Wagner, supra note 87 , at 469 .

217. See supra Part II.C. 
ble in this context. Regulation, rather than litigation or decentralized risk allocation through contract, must be the primary legal mechanism for addressing chemical risks.

\section{B. Toward the Next Generation of Chemical Regulation}

A twenty-first century chemical regulatory regime must have a clear mission, set priorities, and provide EPA with tools to carry out the mission. It must be based on the best scientific information, but should not preclude action where there is residual or unresolvable scientific uncertainty. Below, I sketch the elements of a Strong Precautionary approach to chemical regulation-one that puts the primary burden of risk research and risk justification on chemical manufacturers, while avoiding the parade of horribles predicted by critics of Strong Precaution.

\section{Precautionary Research Requirements}

A Strong Precautionary approach to chemical regulation must include default chemical testing requirements. Indeed, it is hard to see how any chemical regulatory regime could be deemed protective of human health or the environment without an initial, default requirement to compile risk assessment data for most chemicals on the market.

Congress should eliminate the elaborate statutory hurdles in TSCA that restrict EPA's ability to obtain information. Instead, Congress should mandate that chemical manufacturers and importers develop a basic set of toxicity data for each chemical they produce or import above some de minimis tonnage threshold, implementing the principle of "No Data, No Market" in the United States. There should be no distinctions in the required tests for "existing" and "new" chemicals, but the minimum data set could be expanded for the highest-volume chemicals sold in the United States, such as benzene and formaldehyde. Congress could also mandate that manufacturers' testing proceed according to a "priority list" of chemicals suspected of posing the greatest risks, an idea at the heart of the TSCA reform bill introduced by Senator Frank Lautenberg in April 2010. ${ }^{218}$ Imposing the burden of data production on chemical manufacturers would make the profit motive the engine of toxicology re-

218. Safe Chemicals Act of 2010, S. 3209, 111th Cong. § 3(c)(1) (2010). 
search in the United States, ${ }^{219}$ as any chemical for which manufacturers fail to submit the required data would be prohibited from sale. ${ }^{220}$

Critics of Strong Precaution often contend that the Principle is antiinnovation, but they have not elaborated why a requirement that manufacturers research the risks from their own products is suspect, or why such a requirement would interfere with innovation within a firm. In chemical regulation, default testing requirements could actually help to spur product innovation. More abundant information on chemical risks would inform the marketplace, allowing both manufacturers and retailers to compete on product safety as well as product characteristics. ${ }^{221}$

Critics of Strong Precaution also contend that the Principle locks in a "status quo bias." 222 They contend that by adopting a stance of skepticism for new products or technologies, the Principle ignores the risks posed by existing products and technologies. ${ }^{223}$ In chemical regulation, however, it is current law that locks in status quo bias, by grandfathering all "existing" chemicals that were on the market before 1979. To end this unjustifiable distinction, Congress could make the same risk assessment procedures, required on an ex ante premarket basis for new chemicals, applicable to existing chemicals as well. It could do this by providing for a phase-in period of three to five years, which would allow manufacturers to gather data on chemicals already on the market. ${ }^{224}$ There is nothing in the language of the Strong Precautionary Principle that restricts it solely to "new" products or to pioneering technologies. By phasing its review processes for those products and technologies already on the market, the Principle can be adapted to avoid status quo bias.

In chemical regulation, fortunately, the financial barriers to obtaining risk assessment data for existing chemicals have been lowered considerably because most major U.S. chemical manufacturers are already conducting the necessary testing of existing chemicals to comply with the

219. Placing the burden of data production on industry would represent a return to the original vision of TSCA, whose preamble states that development of toxicity data "should be the responsibility of those who manufacture and those who process . . chemical substances and mixtures." TSCA, 15 U.S.C. $\$ 2601$ (b) (2006). The substantive provisions of TSCA, however, place the burden on EPA to prove that testing should be conducted for chemicals already on the market. See id. $\$ 2603$. Wendy Wagner notes that this is just one example of TSCA's "schizophrenic regulatory approach." Wagner, supra note 87, at 464 n.6. See also WILliam H. RogERS, JR., ENVIRONMENTAL LAW 489 (2d ed. 1994) ("TSCA is teeming with contradictions....").

220. To avoid duplicative testing, a new statute should contain provisions for joint research and data sharing, similar to provisions in REACH establishing Substance Information Exchange Fora in the registration process. See REACH, supra note 75, at 104; see also REACH Consortia, CHEMICALWATCH, http://chemicalwatch.com/REACH_consortia (last visited June 2, 2011) (listing joint research consortia that have been established for over one hundred substances).

221. See Sachs, supra note 2, at $\mathbf{1 8 4 0 .}$

222. See, e.g., SUNSTEIN, supra note 12 , at $42-45$.

223. Id.

224. In pharmaceutical regulation, Congress enacted a similar phase-in requirement for drugs already on the market when it amended the FFDCA in 1962 to require that manufacturers prove efficacy as well as safety. See Note, Drug Efficacy and the 1962 Drug Amendments, 60 GEO L. J. 185, 19596 (1972) (describing transitional provisions for drugs already on the market). 
EU's REACH regulation. ${ }^{225}$ Cost estimates for $\mathrm{REACH}$ indicate that the cost of comprehensive toxicity testing for all chemicals on the EU market sold in volumes above ten tons is between $€ 3$ billion and $€ 13$ billion over eleven years, a reasonable cost burden for the global chemical industry, which has annual revenues approaching $\$ 1$ trillion. ${ }^{226}$

The cost estimates for REACH implementation are a significant contribution to the debate over the Strong Precautionary Principle. One of the major criticisms of establishing a licensing system for chemicals, in which manufacturers bear the burden of proof on safety, is that it will impose exorbitant costs on private industry and require an expansion of government risk assessment personnel to review the new data. ${ }^{227}$ But REACH shows that the necessary investments in toxicity testing are not excessively costly given the potential risks and given industry revenues. Private sector research costs in this context should be seen as a fully appropriate internalization of an externality. ${ }^{228}$ Moreover, the cost of overhauling chemical regulation in the United States is likely to be less expensive than in Europe. The United States has a second-mover advantage here, since much of the testing likely to be required of U.S. chemical firms is already being conducted, by these same firms, for REACH compliance.

\section{Shifting the Burden of Proof}

The second major element of a Strong Precautionary approach to chemical regulation is a shift in the burden of proof. If initial required testing demonstrates a serious threat to human health or the environment (as defined below), there should be statutory presumption that the chemical will be banned from sale (or its use restricted). The burden would then shift to the manufacturer to show why that chemical should continue to be marketed in the United States, despite the threat.

Under this regulatory structure, persistent scientific uncertainty about the nature or extent of the risk will be resolved against the chemical, in contrast to current law, in which scientific uncertainty undercuts EPA's ability to enact precautionary restrictions. Moreover, industry will have a financial incentive to resolve scientific uncertainties and to

225. See Sachs, supra note 2, at 1857 (discussing the informational spillover effects of REACH).

226. See id. at 1842-43 (discussing REACH cost estimates).

227. See Valerie J. Brown, REACHing for Chemical Safety, 111 ENVTL. HEALTH PERSP., at A766, A768 (2003) (noting that the critics of REACH argue that "the combination of the increased financial burden of testing, the bureaucracy of registration and authorization, and the requirement of applying the precautionary principle will discourage innovation and could ruin many small and medium-sized enterprises").

228. See Frank Ackerman \& Rachel Massey, Global Dev. \& Env't InSt., The True CosTS OF REACH 10-11 (2004) (arguing that if a chemical essential to downstream users is withdrawn from the market because its manufacturer believes it is not worth paying testing costs, then the chemical is probably underpriced). 
identify means of reducing risks from chemicals with known hazardous properties, to overcome the default regulatory presumption.

To structure this burden shift, Congress should implement both priority-setting mechanisms (which I call "precautionary triggers") and avenues for manufacturers to overcome default prohibitions by demonstrating acceptable risk (which I call "regulatory offramps"). Both are explained in more detail below.

\section{a. Precautionary Triggers}

The task of risk assessment and risk management will quickly become unwieldy if burden shifting is applied to tens of thousands of chemicals simultaneously. If government is to serve as a risk gatekeeper, there must be priority-setting mechanisms, as a matter of practical necessity, to limit the number of products being reviewed at one time. To set priorities and reduce costs, Congress should rely on precautionary triggers for burden shifting, under which the burden of proof would shift to chemical manufacturers only for the subset of high-priority chemicals that meet the trigger, not for the entire universe of chemicals on the market. Focusing on subsets of hazardous chemicals is fully consistent with the Strong Precautionary Principle because, as I argued in Part I, the Principle calls for burden shifting for serious threats to human health and the environment, not for every possible risk. ${ }^{229}$

One such precautionary trigger could be the intrinsic hazards of a chemical, as determined through animal testing, in vitro analysis, ecological fate and transport studies, or computer modeling. Here, the relevant regulatory question is whether the chemical is capable of causing cancer, reproductive harm, or other adverse health or ecosystem effects. The advantage of relying on intrinsic hazard as the threshold inquiry, rather than the actual risk of harm to humans, ${ }^{230}$ is that hazards can be identified relatively easily through laboratory experiments and an understanding of the physical and chemical properties of the substance. Detailed human exposure assessment is not necessary.

Under REACH, chemical hazards that trigger burden shifting in the authorization process include carcinogenicity, mutagenicity, reproductive toxicity, persistence in the environment and the ability of a chemical to accumulate in the food chain. ${ }^{231}$ The European Commission predicts that

229. See supra Part I.

230. Risk is generally characterized as a combination of a chemical's intrinsic hazard and the degree of human exposure. See APPLEGATE ET AL., supra note 13, at 18 . Under the precautionary trig. ger proposed here, intrinsic hazard alone would trigger burden shifting. Exposure issues, including whether safety precautions such as ventilation or protective equipment could reduce human exposures, could then be raised by manufacturers as an argument for why the chemical should not be withdrawn. The overall regulatory architecture would therefore remain risk based, not solely hazard based.

231. REACH, supra note 75 , at 142 . See also APPLEGATE ET AL., supra note 13 , at 23 ("[S]ubstances of very high concern should, in accordance with the precautionary principle, be subject 
approximately 1500 chemicals, or five percent of the 30,000 chemicals expected to be registered under the law, will fall into this "very high concern" category. ${ }^{232}$ A Strong Precautionary regime needs some mechanism for delineating the class of chemicals that will be deemed to pose "serious" threats, and intrinsic hazard is a logical, feasible starting point for that line drawing. TSCA, on the other hand, provides no mechanism for deciding which characteristics of chemicals should trigger further inquiry or a regulatory response other than the vague framework of "unreasonable risk."

A second potential trigger for burden shifting could be the results of biomonitoring studies. Biomonitoring is the study of the presence of industrial chemicals in humans. In several studies in the past decade, the Centers for Disease Control and Prevention has demonstrated that dozens of industrial chemicals are commonly found in the blood and urine of representative samples of the U.S. population. ${ }^{233}$ The Environmental Working Group, in its own testing, found that of 210 synthetic chemicals tested in a population of nine volunteers, 167 chemicals were found in at least one person, and some chemicals, such as brominated flame retardants, were present in nearly all the volunteers. ${ }^{234}$ Most prior biomonitoring studies have had limited sample sizes, ${ }^{235}$ but if they were significantly expanded, the data could be used to compile a list of synthetic chemicals commonly found in Americans. These chemicals could then be presumed unsafe - the precautionary trigger. The burden of proof for continued marketing of this class of chemicals would then switch to manufacturers, on the grounds that manufacturers should have an affirmative obligation to demonstrate that chemicals widely dispersed inside our bodies are not causing any substantial harm to human health.

The American Chemistry Council challenges the regulatory utility of biomonitoring data, claiming that it "provide[s] a snapshot of the U.S. population's exposure to certain substances in our environment," and that "the detection of a substance does not by itself indicate a safety concern." 236 To be sure, the presence of an industrial chemical in human tissues does not by itself indicate harm, but given the widespread uptake of

to careful attention."). Similarly, the Maine Toxic Chemicals in Children's Products Act classifies chemicals of "high concern" as those that can cause cancer or reproductive or developmental harm; those that disrupt the endocrine system; and those that are persistent, bioaccumulative, and toxic. ME. REV. STAT. tit. 38, § 1693 (2010).

232. $Q$ and $A$ on the New Chemicals Policy, REACH, EUROPA (Dec. 13, 2006), http://europa.eu/ $\mathrm{rapid} /$ pressReleases Action.do? reference=MEMO/06/488.

233. See generally DEP'T OF HEALTH \& HUMAN SERVS. ET AL., supra note 4 (discussing the use of biomonitoring to track the U.S. population's exposure to environmental chemicals).

234. See Jane Houlihan ET Al., ENVTL. WORKING GRP., BodyBurden: THE POllution IN PEOPLE 3, 38-39 (2003).

235. See Denison, supra note 4, at 10025 ("Government has yet to conduct broader, more exploratory biomonitoring - aimed at identifying the full range of xenobiotics to which humans are exposed, as one means of identifying chemicals that are priorities for further scrutiny ....").

236. Biomonitoring, AM. CHEMISTRY COUNCIL, http://www.americanchemistry.com/biomon itoring (last visited June 2, 2011). 
certain chemicals by humans, that presence should at least trigger a shift in the burden in proof-an affirmative requirement to prove the lack of substantial harm. ${ }^{237}$

\section{b. Regulatory Offramps}

Strong Precaution does not require banning all risky products or activities, nor does it require banning all chemicals with intrinsically hazardous characteristics. Many hazardous compounds offer important benefits for the economy and human welfare. For example, mercury, a potent neurotoxin, is used to make compact fluorescent light bulbs and flat-panel computer monitors. Properly construed, the Strong Precautionary Principle should provide an opportunity for a chemical manufacturer to justify why marketing of a chemical should be permitted, overcoming any default presumption against sale. In a successor statute to TSCA, manufacturers should be provided an opportunity to show that a chemical with hazardous characteristics should still be permitted to be marketed because: (1) the actual risks to human health or the environment are not substantial, (2) the risks can be controlled through limiting exposure, or (3) the benefits of the chemical to society outweigh any risk.

Through these provisions, the overall regulatory structure would remain focused on the actual risks of a chemical to human health and the environment, not just on the intrinsic properties of the chemical. A manufacturer could demonstrate, for example, that a substance, although hazardous in laboratory tests on rodents, actually poses no substantial risk to humans or ecosystems because of the way it is used commercially (e.g., that it is sealed in polymers; that there is limited potential for inhalation, digestion, or dermal exposures; or that environmental releases can be prevented through proper disposal in a licensed facility). These provisions, moreover, would allow some weighing of the risks of a chemical against its benefits, within an overarching regulatory system grounded in Strong Precaution. In contrast to current law, however, the manufacturer, rather than the government, would conduct the cost-benefit analysis and bear the burden of proof.

I refer to these mechanisms as "regulatory offramps." They help to counter the charge of many critics that Strong Precaution is a straightjacketing approach that offers no regulatory flexibility. They also alle-

237. One of the TSCA reform bills from the last Congress, the Safe Chemicals Act, relied heavily on precautionary burden shifting. Safe Chemicals Act of 2010, S. 3209, 111th Cong. $\$ 7$ (2010). It required EPA, within eighteen months after enactment, to establish a rotating "priority list" of 300 substances. Id. For any substance on that list, the burden would switch to the manufacturer to prove a "reasonable certainty of no harm." Id. $\S \S 4,7$. The bill stated that chemical substances should be added to list "at the Administrator's discretion, based on available scientific evidence, and consideration of their risk relative to other chemical substances, based upon presence in biological and environmental media, use, production volume, toxicity, persistence, bioaccumulation, or other properties indicating risk." Id. $\$ 7$. 
viate concerns about risk-risk tradeoffs, because if significant economic damage or welfare loss will result from restrictions on a chemical, the manufacturer will have the opportunity to make the case that restrictions are unwarranted.

As noted in Part II, the EU has pioneered use of regulatory offramps in $\mathrm{REACH} .{ }^{238}$ Under $\mathrm{REACH}$, regulators may grant a timelimited authorization to continue to market a "very high concern" chemical if the manufacturer or importer can demonstrate that the risks to human health and the environment are "adequately controlled," or if this showing cannot be made, ${ }^{239}$ the manufacturer or importer must demonstrate: (1) that the socio-economic benefits exceed the risks, and (2) that are no suitable substitute chemicals or technologies. ${ }^{240}$

Regulatory offramps should be a component of chemical regulation in the United States, but in implementing offramps, regulators should not take at face value manufacturers' arguments that known hazardous chemicals actually present little risk because exposures are minimal or because risks can be controlled through warnings. Historically, the United States has done a poor job of tracking uses and exposures to chemicals once chemicals are put on the market. Because many of the most hazardous classes of chemicals also persist in the environment for decades, it can be difficult to predict the degree of human exposure over time. ${ }^{241}$

Substitution analysis should also be a required component of the regulatory offramp process. If a chemical manufacturer seeks to market a chemical with known hazardous properties or that is already widely present in the bodies of Americans, it should also have an obligation to investigate whether any less hazardous substitute chemicals are available that could serve the same purpose. An improved chemical regulatory regime should not only require scientifically sound analysis of the risks of a particular chemical, but also incentivize reductions in the use of all hazardous chemicals over time.

238. See supra Part H.B.3.c.

239. REACH presumes that risks cannot be adequately controlled for persistent and bioaccumulative chemicals and for chemicals that do not have a known safe threshold below which a lack of adverse effects can be documented. REACH, supra note 75, at 153 .

240. Id. at 150 .

241. See TSCA and Persistent, Bioaccumulative, and Toxic Chemicals: Examining Domestic and International Actions: Hearing Before the Subcomm. on Commerce, Trade and Consumer Prot., U.S. Cong. Comm. on Energy and Commerce, 111th Cong. 2 (2010) (testimony of Linda E. Greer, Director, Health and Environment Program, Natural Resources Defense Council) ("Because risk assessments require a quantification of exposure levels, and because the levels of [Persistent, Bioaccumulative, and Toxic compounds] will continue to rise for as long as the contaminant is released into the environment or the food chain, [regulators] cannot adequately evaluate the harm posed by this class of compounds."). 


\section{CONCLUSION}

The Strong Precautionary Principle provides a useful framework for managing risk in the face of scientific uncertainty. Widely derided as inflexible, unworkable, counterproductive, or anti-innovation, the Principle has been consistently attacked in the academic literature on risk regulation. Yet, as this Article has shown, the Principle already animates many successful risk regulatory regimes in the United States. It is not blind to risk-risk tradeoffs, nor must it ignore the cost of regulation. The Principle does reflect, however, the intuition that those who introduce potentially risky products to the marketplace should bear the burden of researching and justifying the risks. The Principle is particularly useful in areas such as chemical regulation, where there is a potential for serious harm, where there is scientific uncertainty about the nature of risk, and where less aggressive, decentralized mechanisms are clearly inadequate to address the risk.

Chemical regulation provides a helpful case study of the Principle's utility in risk management. Widely viewed as a "broken statute,"242 the current TSCA regime needs more than incremental reform. Shifting the burden of proof would dramatically alter the perverse incentives of the existing statute and would end the data drought that has plagued chemical regulation since the 1970s. A fundamental rethinking of chemical regulation is urgently needed, and the Strong Precautionary Principle provides a sound theoretical basis for protecting public health and reforming TSCA's unprotective, unprecautionary approach.

242. Greenwood, supra note 207 , at 10034 . 